\title{
Green and Reliable Freight Routing Problem in the Road-Rail Intermodal Transportation Network with Uncertain Parameters: A Fuzzy Goal Programming Approach
}

\author{
Yan Sun ii \\ School of Management Science and Engineering, Shandong University of Finance and Economics, No. 7366, \\ Second Ring East Road, Jinan, Shandong Province 250014, China \\ Correspondence should be addressed to Yan Sun; sunyanbjtu@163.com
}

Received 9 September 2019; Accepted 8 January 2020; Published 19 February 2020

Academic Editor: Yuchuan Du

Copyright (c) 2020 Yan Sun. This is an open access article distributed under the Creative Commons Attribution License, which permits unrestricted use, distribution, and reproduction in any medium, provided the original work is properly cited.

In this study, the author focuses on modeling and optimizing a freight routing problem in a road-rail intermodal transportation network that combines the hub-and-spoke and point-to-point structures. The operations of road transportation are time flexible, while rail transportation has fixed departure times. The reliability of the routing is improved by modeling the uncertainty of the roadrail intermodal transportation network. Parameters that are influenced by the real-time status of the network, including capacities, travel times, loading and unloading times, and container trains' fixed departure times, are considered uncertain in the routing decision-making. Based on fuzzy set theory, triangular fuzzy numbers are employed to formulate the uncertain parameters as well as resulting uncertain variables. Green routing is also discussed by treating the minimization of carbon dioxide emissions as an objective. First of all, a multiobjective fuzzy mixed integer nonlinear programming model is established for the specific reliable and green routing problem. Then, defuzzification, linearization, and weighted sum method are implemented to present a crisp linear model whose global optimum solutions can be effectively obtained by the exact solution algorithm run by mathematical programming software. Finally, a numerical case is given to demonstrate how the proposed methods work. In the case, sensitivity analysis is adopted to reveal the effects of uncertainty on the routing optimization. Fuzzy simulation is then performed to help decision makers to select the best crisp route plan by determining the best confidence level shown in the fuzzy chance constraints.

\section{Introduction}

Rail transportation has been acknowledged to be a costeffective means of long-distribution transportation. It yields massive capacity and can effectively realize the economies of scale in bulk transportation [1]. As another representative transportation mode, road transportation shows excellent mobility and flexibility in short- and medium-distance collection and delivery activities [2]. Coordination of the two transportation modes in one distribution chain in which the loading units are ISO standard $20 \mathrm{ft}$ containers [3] leads to an advanced transportation system named road-rail intermodal transportation.

Road-rail transportation combines the above two transportation modes and integrates their respective advantages to provide seamless door-to-door services for containerized freight delivery that are difficult to achieve by the unimodal transportation [4]. In recent years, road-rail intermodal transportation has become a promising means of inland freight transportation in the Euro-China Expressway to support the growing international trade motivated by the development of the "One Belt, One Road" initiatives [5]. The road-rail intermodal transportation system has been thereby widely established and promoted not only in transportation practice, but also in logistics [6] and supply chain [7].

To realize effective resource allocation and utilization, as well as successful operations of the road-rail intermodal transportation system, it is necessary to use modeling, optimization, and simulation methods and techniques to help decision makers (e.g., transportation planners, intermodal transportation operators, policy makers, and transportation providers and customers) to establish an 
optimal transportation network in strategic, tactical, and operational levels [8]. As summarized by Caris et al. [9], recent research topics in the road-rail intermodal transportation planning field include policy support, terminal network design, intermodal service network design, intermodal routing, and drayage operations. Among these topics, road-rail intermodal routing that belongs to operational-level planning is a spotlight highlighted by researchers in theory and practitioners in transportation practice [10] and is the issue targeted by this study.

Road-rail intermodal routing involves the optimal utilization of existing transportation resources that are limited in the road-rail intermodal transportation network. It aims at the selection of the best routes to move containers of transportation orders demanded by customers from origins to destinations through the road-rail intermodal transportation network [11]. The best routes can either achieve optimum on any one of the objectives, e.g., minimal cost $[3,12,13]$, minimal time $[14,15]$, lowest risk $[16,17]$, and minimal greenhouse gas emissions [18], or make tradeoffs among them in multiobjective optimizations.

Since logistics cost accounts for as much as 30\% to $50 \%$ of the total production cost of companies [14, 19], reducing costs created in the road-rail intermodal transportation process is the main task of its routing optimization, which also motivates that majority of the relative literature takes minimization of costs as a prior optimization objective [2]. Simultaneously, as a great contributor to greenhouse gas emissions that cause global warming, the transportation industry has been urgently demanded for an environmental-friendly development [20-22]. In this case, the transportation industry is challenged by reducing environmental impact while keeping profitable [23]. As stated by Winebrake et al. [20], planning routes with environmental considerations through the intermodal transportation system is an effective way to improve the environmental sustainability of transportation. Carbon dioxide accounts for $\sim 80 \%$ of the total greenhouse gas emissions [24]. This study investigates a green road-rail intermodal routing problem considering the reduction of carbon dioxide emissions.

Reliability is a crucial issue that is involved in the intermodal transportation system that needs to coordinate various transportation modes, large number of facilities, and different actors in an extensive network that is under a more complicated environment than unimodal transportation $[18,25]$. In the road-rail intermodal routing problem, reliability means the successful accomplishment of transportation orders by using planned road-rail intermodal routes [26]. Uncertainty is the primary factor that influences the reliability of intermodal transportation [27-29]. Although a short-term planning [8], the routing optimization should be undertaken before the actual transportation starts [30]. However, the operations of the transportation network are easily disrupted by various factors, such as bad weather, traffic congestion, accidents, breakdown or shortage of transportation facilities, and so on [26]. As a result, network parameters regarding operational times and service capacities that are exceedingly sensitive to the real-time status of the transportation network cannot keep stable and are also challenging to be forecasted precisely in the advanced routing decisionmaking, which results in the uncertainty of the intermodal transportation network. Therefore, this study discusses the reliable road-rail intermodal routing problem under uncertainty in this study.

Above all, in this study, the author systematically explores a green and reliable road-rail intermodal routing problem by making the following contributions:

(1) A road-rail intermodal routing problem is extended by enhancing its environmental sustainability with carbon dioxide emission optimization and improving transportation reliability with multiple sources of uncertainty.

(2) Based on the fuzzy set theory, triangular fuzzy numbers are adopted to model the uncertainty of the road-rail intermodal transportation network, including capacities, travel times, loading and unloading times, and fixed departure times. Multiobjective optimization is employed to deal with the carbon dioxide emissions by generating Pareto solutions to make tradeoffs between the economic and environmental objectives.

(3) Fuzzy goal programming approach is used to formulate the green and reliable freight routing problem in the road-rail intermodal transportation network with hub-and-spoke and point-to-point structures. A multiobjective fuzzy mixed integer nonlinear programming model is established, and associated exact solution approach is developed.

(4) The proposed methods are demonstrated in a numerical case, in which sensitivity analysis and fuzzy simulation are utilized to analyze the effects of transportation network uncertainty on the routing optimization quantitatively, and finally, determine the optimum confidence level in the fuzzy chance constraints.

The remaining sections of this study are organized as follows. Section 2 reviews relative literature in order to find the research gap and identify the contributions of this study. Section 3 provides the modeling foundation for the road-rail intermodal routing problem, including modeling network uncertainty by fuzzy set theory and formulating the transportation system. Section 4 presents a multiobjective fuzzy mixed integer nonlinear programming model for the specific green and reliable routing problem. Then, an exact solution approach that combines defuzzification, linearization, and the weighted sum method is designed for the sake of obtaining the global optimum solutions to the problem. A numerical case is given in Section 6 to demonstrate the feasibility of the proposed fuzzy goal programming approach. This study also uses sensitivity analysis and fuzzy simulation to quantify the effects of transportation network uncertainty on the routing optimization in this section. Finally, conclusions and insights are drawn in Section 7. 


\section{Literature Review}

Although Caris et al. [9] pointed out in 2013 that few studies pay attention to the intermodal routing problem, many relative types of research on this topic published in recent years can be found.

2.1. Review on Green Intermodal Routing Problem. As an effective way to improve the environmental sustainability of the intermodal transportation system, the green routing problem with carbon dioxide emission consideration is paid growing attention by existing literature. Carbon tax regulation might be the most widely used method in the green intermodal routing problem to reduce carbon dioxide emissions [31]. Under carbon tax regulation, transportation orders are charged for each unit of emission with a tax [32]. The tax is then integrated into the economic objective. By optimizing the economic objective, the carbon dioxide emission tax has opportunities to be reduced, which can help to lower carbon dioxide emissions in the routing.

As a simple and straightforward method, carbon tax regulation has been used by Chang et al. [33] in modeling a sea-land intermodal routing problem with external cost. Sun and Lang [34] and Zhang et al. [35] also adopt this regulation in a multicommodity multimodal routing problem and a transportation mode selection problem in intermodal transportation, respectively. Hrušovský et al. [36] explore a green intermodal routing problem with travel time uncertainty in which the carbon dioxide emission tax is a part of the economic objective and is also attached to weight associated with decision makers' preference to the environmental sustainability of transportation. It is also employed by Zhang et al. [37] in a green multimodal routing problem with time windows. In this study, sensitivity of the green routing optimization on the unit carbon tax is analyzed, which shows that the performance of carbon tax regulation is sensitive to the setting of time windows. Sun et al. [11] discuss a green intermodal routing problem with capacity uncertainty and road traffic congestion. The empirical case study presented in this study indicates that the green routing optimization is not sensitive to the unit emission tax, and the routes are not changed unless the unit emission tax reach a substantial value that is infeasible in practice.

Since the performance of carbon dioxide emission regulation depends on the setting of routing cases [36] and is not always stable [11], finding an alternative for the green intermodal routing problem is necessary. Currently, a few articles try multiobjective optimization to reduce the carbon dioxide emissions in the intermodal routing. Vale and Ribeiro [38] propose a multiobjective model for a multimodal routing problem, in which minimization of carbon dioxide emissions is set as an objective that is independent of the objective of minimizing the transportation time. Demir et al. [18] also employ multiobjective optimization for reducing carbon dioxide-equivalent emissions in the intermodal routing, in which several methods that can be used to generate the Pareto solutions to the green routing optimization are tested. Moreover, in the case study given by Sun et al. [11], multiobjective optimization that can provide decision makers with Pareto solutions to the green routing problem shows better feasibility than carbon tax regulation in making tradeoffs between improving environmental sustainability and lowering logistics cost. Besides the intermodal routing problem, limited researches on the intermodal transportation network design problem also utilize multiobjective optimization to realize the design of green intermodal transportation network, e.g., Qu et al. [39] and Resat and Turkay [40].

Additionally, Sun et al. [31] establish a carbon dioxide emission constraint in the hazardous materials road-rail multimodal routing problem. This constraint ensures the carbon dioxide emissions generated by the hazardous materials road-rail multimodal transportation using the planned routes kept lower than a prescribed threshold. Sensitivity analysis on the routing optimization concerning the allowable carbon dioxide emissions in this study indicates that the carbon dioxide emission constraint has nearly the same performance to the multiobjective optimization.

\subsection{Review on Reliable Intermodal Routing Problem under} Uncertainty. Transportation process optimization should take uncertainty into account [41, 42]. As indicated in Section 1, parameters that are sensitive to the real-time status of the road-rail intermodal transportation network are uncertainty in the routing decision-making. However, the deterministic intermodal routing problem is still the current dominance. Large numbers of deterministic routing optimizations can be found from early studies, e.g., Barnhart and Ratliff [43], Boardman et al. [44], Bookbinder and Fox [45], and Ziliaskopoulos and Wardell [46] to recently published articles, e.g., Chang et al. [14], Xiong and Wang [15], Sun and Lang [34], Ayar and Yaman [47], Moccia et al. [48], Heggen et al. [49], and Wolfinger et al. [50]. A few studies contribute to the intermodal routing problem under uncertainty [3].

In the intermodal routing problem under uncertainty, travel time uncertainty gains the most extensive attention. Majority of the relative studies focuses on the intermodal routing problem under travel time uncertainty. An early study conducted by Min [51] developed a stochastic chance-constrained programming model to solve the intermodal routing problem with travel time uncertainty. A similar approach is employed by Zhao et al. [3] to find the best sea-rail intermodal routes with stochastic travel times in a space-time network and by Uddin and Huynh [13, 27] in the real-world road-rail intermodal transportation system. Hrušovský et al. [36] also take advantage of stochastic programming and design a hybrid simulation and optimization approach for the green intermodal routing problem with travel time uncertainty. Conducted by the same group of authors to Hrušovský et al. [36], there is a study that uses stochastic programming to address a green intermodal transportation network design problem that considers travel times as uncertain parameters [22]. Based on the fuzzy set theory, Sun and Li [2] establish a fuzzy programming model to formulate a road-rail intermodal routing problem with road travel time fuzziness. Similarly, 
fuzzy programming method is also utilized by Wang et al. [1] in optimizing a road-rail intermodal hub-and-spoke network design problem in which travel times are one of several uncertain network parameters.

Other intermodal transportation network time parameters receive limited interests from routing optimization. Loading and unloading time uncertainty (fuzziness) is studied by Sun and $\mathrm{Li}$ [2] together with road travel time uncertainty in the road-rail intermodal routing problem. Transfer times between different transportation modes are considered as stochastic parameters by Zhao et al. [3] in their relative study. As stressed by various studies, e.g., Demir et al. [18], Hrušovský et al. [36], Moccia et al. [48], and Heinold and Meisel [52], there are some transportation modes, e.g., rail and vessel that should be operated by fixed departure times. Fixed departure times are sensitive to the real-time status of operations of associated transportation modes at terminals under disruptions claimed in Section 1 and detailly explained in Section 3. Therefore, the departures of container trains from terminals are not always punctual and thus are also uncertain. However, to the best of our knowledge, there is no existing literature that considers this issue in the intermodal routing problem.

Besides time parameters, the capacity of the intermodal transportation network is also uncertain $[11,30]$, while few studies can be found. Sun et al. [30] systematically investigate the effects of capacity uncertainty on the intermodal routing optimization from a fuzzy programming perspective. There is also a study [30] that considers capacity fuzziness in a green intermodal routing problem. Although the intermodal routing problem pays limited attention, capacity uncertainty is highlighted by the solid transportation problem [53-55] and supply chain planning problem [56, 57]. A combination of multiple sources of uncertainty can remarkably improve the planning reliability [2]. As a result, this study will comprehensively model the road-rail intermodal transportation network uncertainty by considering capacities, fixed departure times, travel times, and loading and unloading times as uncertain parameters.

Stochastic programming is widely used to deal with uncertain optimization problems in the transportation planning field, e.g., Uddin and Huynh [13], Demir et al. [18], and Hrušovský et al. [36]. Large numbers of reliable previous data must be attained to fit the possibility distributions for uncertain parameters $[58,59]$. However, in most practical cases, the previous data are missing or vague [60]. Consequently, there is not enough data to carry out stochastic programming. Its feasibility is hence reduced. As claimed by Zarandi et al. [58], fuzzy set theory and fuzzy programming are effective alternatives to stochastic programming when data availability is limited. The previous data of an uncertain parameter usually fall into a particular range. Based on the fuzzy set theory, decision makers can define uncertain parameters as fuzzy numbers, e.g., triangular fuzzy numbers, by referring to the expert experience and limited previous data. After that, fuzzy programming approaches, e.g., fuzzy chance-constrained programming, can be used to establish optimization models for the uncertain optimization problems. As a result, in this study, fuzzy programming is selected to address the intermodal routing problem associated with uncertain parameters.

2.3. Review Overview. Above all, an overall comparison between this study and relevant existing literature is presented in Table 1. With the help of Table 1, improvements made by this study can be clearly identified.

\section{Modeling Foundation}

In this section, the author systematically introduces how this study models the uncertainty and the road-rail intermodal transportation system, which provides a modeling foundation for building the optimization model in the next section.

\subsection{Modeling Road-Rail Intermodal Transportation Network} Uncertainty. As claimed in Section 2, in this study, the author uses the fuzzy set theory to model the uncertain parameters and resulting uncertain decision variables. Triangular fuzzy numbers are used to describe the fuzzy parameters and decision variables due to its better simplicity and flexibility in fuzzy arithmetic operations than interval and trapezoidal fuzzy numbers that are other widely used forms of fuzzy numbers [57]. Triangular fuzzy numbers adopt three prominent points, including minimum, most likely, and maximum estimations, to represent the fuzziness [2], and comprehensively show decision makers' pessimistic, optimistic, and most likely opinions on fuzzy events, which can be seen in Figure 1. Specifically, as for the uncertain parameters in the road-rail intermodal transportation system, the three prominent points are defined as follows.

For minimum estimation on the network parameters, it reflects the road-rail intermodal transportation system under following situations that are slightly possible in practice: (i) the road and rail traffic is in a quite good status, and moving constrainers from one node to another one can be rapidly realized; (ii) the operations of trucks and trains at the rail terminal are of high efficiency, i.e., loading and unloading operations can be finished rapidly by using enough mechanical equipment handled by enough skilled staff, and the work that need to be undertaken before the departure of the container trains can be finished in a short period; (iii) the transportation network, however, is faced with lousy capacity availability. For example, large numbers of container trucks and trains might be occupied by other tasks [30].

For most likely estimation, it represents the usual status of the road-rail intermodal transportation system. The road and rail traffic, the operations of trucks and trains at rail terminals, and the network capacity are in common situations that are neither too good nor too bad. Under such status, the parameters of the network yield values appear in most cases.

For maximum estimation, it is contrary to minimum estimation. It represents the following situations that are also slightly possible in practice: (i) the road and rail traffic is in a terrible status that might be caused by congestion, bad weather, or accidents, which result in the slow movement of 
TABLE 1: Comparison between the existing literature and this study.

\begin{tabular}{|c|c|c|c|c|c|c|c|}
\hline \multirow[b]{2}{*}{ Authors } & \multirow[b]{2}{*}{ Year } & \multicolumn{6}{|c|}{ Uncertain parameters in reliable routing under uncertainty } \\
\hline & & $\begin{array}{l}\text { Methods for green } \\
\text { routing }\end{array}$ & Capacities & $\begin{array}{c}\text { Fixed } \\
\text { departure } \\
\text { times }\end{array}$ & $\begin{array}{l}\text { Travel } \\
\text { times }\end{array}$ & $\begin{array}{l}\text { Loading and } \\
\text { unloading times }\end{array}$ & Modeling approach \\
\hline $\operatorname{Min}[51]$ & 1991 & $x$ & $x$ & $x$ & $\checkmark$ & $x$ & $\begin{array}{c}\text { Stochastic } \\
\text { programming }\end{array}$ \\
\hline $\begin{array}{l}\text { Barnhart and Ratliff } \\
\text { [43] }\end{array}$ & 1993 & $x$ & $x$ & $x$ & $x$ & $x$ & $\begin{array}{l}\text { Deterministic } \\
\text { programming }\end{array}$ \\
\hline Boardman et al. [44] & 1997 & $x$ & $x$ & $x$ & $x$ & $x$ & $\begin{array}{l}\text { Deterministic } \\
\text { programming }\end{array}$ \\
\hline $\begin{array}{l}\text { Bookbinder and Fox } \\
\text { [45] }\end{array}$ & 1998 & $x$ & $x$ & $x$ & $x$ & $x$ & $\begin{array}{l}\text { Deterministic } \\
\text { programming }\end{array}$ \\
\hline $\begin{array}{l}\text { Ziliaskopoulos and } \\
\text { Wardell [46] }\end{array}$ & 2000 & $x$ & $x$ & $x$ & $x$ & $x$ & $\begin{array}{l}\text { Deterministic } \\
\text { programming }\end{array}$ \\
\hline Chang [14] & 2008 & $x$ & $x$ & $x$ & $x$ & $x$ & $\begin{array}{l}\text { Deterministic } \\
\text { programming }\end{array}$ \\
\hline Chang et al. [33] & 2010 & $\begin{array}{l}\text { Carbon tax } \\
\text { regulation }\end{array}$ & $x$ & $x$ & $x$ & $x$ & $\begin{array}{l}\text { Deterministic } \\
\text { programming }\end{array}$ \\
\hline Zhang et al. [35] & 2011 & $\begin{array}{l}\text { Carbon tax } \\
\text { regulation }\end{array}$ & $x$ & $x$ & $x$ & $x$ & $\begin{array}{l}\text { Deterministic } \\
\text { programming }\end{array}$ \\
\hline Moccia et al. [48] & 2011 & $x$ & $x$ & $x$ & $x$ & $x$ & $\begin{array}{l}\text { Deterministic } \\
\text { programming }\end{array}$ \\
\hline Verma et al. [17] & 2012 & $x$ & $x$ & $x$ & $x$ & $x$ & $\begin{array}{l}\text { Deterministic } \\
\text { programming }\end{array}$ \\
\hline Ayar and Yaman [47] & 2012 & $x$ & $x$ & $x$ & $x$ & $x$ & $\begin{array}{l}\text { Deterministic } \\
\text { programming }\end{array}$ \\
\hline Xiong and Wang [15] & 2014 & $x$ & $x$ & $x$ & $x$ & $x$ & $\begin{array}{l}\text { Deterministic } \\
\text { programming }\end{array}$ \\
\hline Sun and Lang [12] & 2015 & $\begin{array}{l}\text { Carbon tax } \\
\text { regulation }\end{array}$ & $x$ & $x$ & $x$ & $x$ & $\begin{array}{l}\text { Deterministic } \\
\text { programming }\end{array}$ \\
\hline Sun and Lang [34] & 2015 & $x$ & $x$ & $x$ & $x$ & $x$ & $\begin{array}{l}\text { Deterministic } \\
\text { programming }\end{array}$ \\
\hline $\begin{array}{l}\text { Uddin and Huynh } \\
\text { [27] }\end{array}$ & 2016 & $x$ & $x$ & $x$ & $\checkmark$ & $x$ & $\begin{array}{l}\text { Stochastic } \\
\text { programming }\end{array}$ \\
\hline Zhang et al. [37] & 2017 & $\begin{array}{l}\text { Carbon tax } \\
\text { regulation }\end{array}$ & $x$ & $x$ & $x$ & $x$ & $\begin{array}{l}\text { Deterministic } \\
\text { programming }\end{array}$ \\
\hline Zhao et al. [3] & 2018 & $x$ & $x$ & $x$ & $\checkmark$ & $\begin{array}{c}\boldsymbol{J} \text { (transfer time } \\
\text { uncertainty) }\end{array}$ & $\begin{array}{l}\text { Stochastic } \\
\text { programming }\end{array}$ \\
\hline Sun et al. [11] & 2018 & $\begin{array}{l}\text { Carbon tax } \\
\text { regulation }\end{array}$ & $\checkmark$ & $x$ & $\checkmark$ & $x$ & $\begin{array}{c}\text { Time-dependent fuzzy } \\
\text { programming }\end{array}$ \\
\hline Sun et al. [30] & 2018 & $x$ & $\checkmark$ & $x$ & $x$ & $x$ & Fuzzy programming \\
\hline Hrušovský et al. [36] & 2018 & $\begin{array}{l}\text { Carbon tax } \\
\text { regulation }\end{array}$ & $x$ & $x$ & $\checkmark$ & $x$ & $\begin{array}{l}\text { Stochastic } \\
\text { programming }\end{array}$ \\
\hline Vale and Ribeiro [38] & 2018 & $\begin{array}{l}\text { Multiobjective } \\
\text { optimization }\end{array}$ & $x$ & $x$ & $x$ & $x$ & $\begin{array}{l}\text { Deterministic } \\
\text { programming }\end{array}$ \\
\hline Wolfinger et al. [50] & 2018 & $x$ & $x$ & $x$ & $x$ & $x$ & $\begin{array}{l}\text { Deterministic } \\
\text { programming }\end{array}$ \\
\hline Sun and $\mathrm{Li}[2]$ & 2019 & $x$ & $x$ & $x$ & $\checkmark$ & $\checkmark$ & Fuzzy programming \\
\hline $\begin{array}{l}\text { Uddin and Huynh } \\
\text { [13] }\end{array}$ & 2019 & $x$ & $x$ & $x$ & $\checkmark$ & $x$ & $\begin{array}{l}\text { Stochastic } \\
\text { programming }\end{array}$ \\
\hline Demir et al. [18] & 2019 & $\begin{array}{l}\text { Multiobjective } \\
\text { optimization }\end{array}$ & $x$ & $x$ & $x$ & $x$ & $\begin{array}{l}\text { Deterministic } \\
\text { programming }\end{array}$ \\
\hline Rivera et al. [23] & 2019 & $x$ & $x$ & $x$ & $x$ & $x$ & $\begin{array}{l}\text { Deterministic } \\
\text { programming }\end{array}$ \\
\hline Sun et al. [31] & 2019 & $\begin{array}{l}\text { Carbon emission } \\
\text { constraint }\end{array}$ & $x$ & $x$ & $x$ & $x$ & $\begin{array}{l}\text { Deterministic } \\
\text { programming }\end{array}$ \\
\hline Heggen et al. [49] & 2019 & $x$ & $x$ & $x$ & $x$ & $x$ & $\begin{array}{l}\text { Deterministic } \\
\text { programming }\end{array}$ \\
\hline This study & & $\begin{array}{l}\text { Multiobjective } \\
\text { optimization }\end{array}$ & $\checkmark$ & $\checkmark$ & $\checkmark$ & $\checkmark$ & $\begin{array}{l}\text { Fuzzy goal } \\
\text { programming }\end{array}$ \\
\hline
\end{tabular}




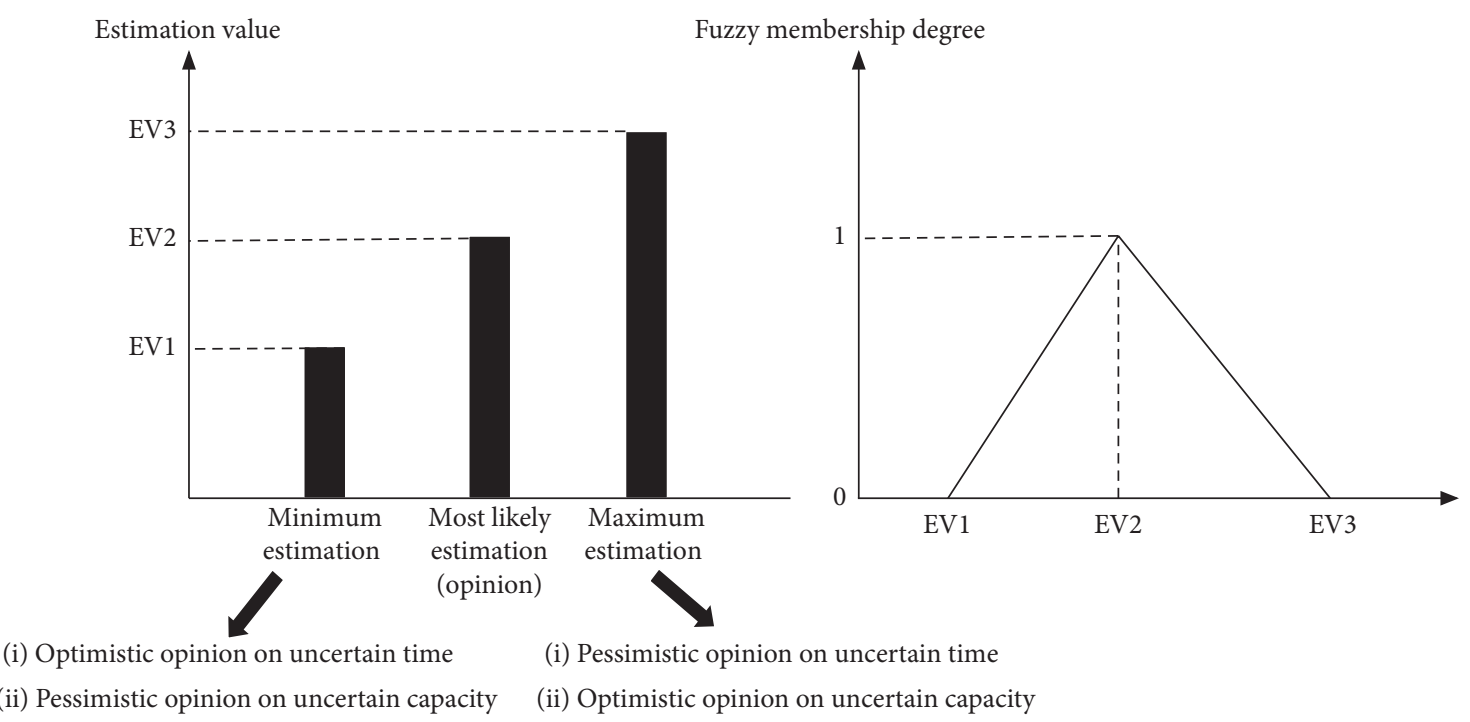

FIgure 1: A triangular fuzzy number.

containers on transportation lines. (ii) The operations of trucks and trains are delayed by information errors, mechanical breakdown, shortage of equipment or staff, or unskilled handling of inexperienced workers. (iii) The transportation network has adequate equipment and facility resources for carrying containers.

Above all, triangular fuzzy numbers are feasible to represent the different status of the road-rail intermodal transportation system and can thus fully reflect the uncertainty of the network parameters.

Additionally, fuzzy chance-constrained programming modeling and associated defuzzification involve some fuzzy arithmetic operations of triangular fuzzy numbers. These operations are presented as follows, where $\widetilde{m}=\left(m_{1}, m_{2}, m_{3}\right)$ and $\tilde{n}=\left(n_{1}, n_{2}, n_{3}\right)$ are the triangular fuzzy numbers and $a$ is a non-negative deterministic number:

$$
\begin{aligned}
\widetilde{m}+\widetilde{n} & =\left(m_{1}, m_{2}, m_{3}\right)+\left(n_{1}, n_{2}, n_{3}\right) \\
& =\left(m_{1}+n_{1}, m_{2}+n_{2}, m_{3}+n_{3}\right), \\
\widetilde{m}-\tilde{n} & =\left(m_{1}, m_{2}, m_{3}\right)-\left(n_{1}, n_{2}, n_{3}\right) \\
& =\left(m_{1}-n_{3}, m_{2}-n_{2}, m_{3}-n_{1}\right), \\
a \cdot \tilde{n} & =a \cdot\left(n_{1}, n_{2}, n_{3}\right)=\left(a \cdot n_{1}, a \cdot n_{2}, a \cdot n_{3}\right) .
\end{aligned}
$$

\subsection{Modeling Road-Rail Intermodal Transportation System.} Road-rail intermodal routing problem is more complicated than the classical vehicle routing problem. It should determine the consolidation network of the road-rail transportation system that is more complex than the lessthan-truck-load system of vehicle routing and model the different transportation modes instead of only considering one transportation mode, i.e., trucks, in vehicle routing. The question of how to coordinate the two different transportation modes also improves the complexity of the road-rail intermodal routing. The road-rail intermodal transportation system in this study shows the following characteristics:

(1) Consolidation network of the system contains huband-spoke structures (prehaul by trucks, long haul by trains, and end haul by trucks) that is considered as the most suitable physical construction for roadrail intermodal transportation [1] and point-to-point structures (all-road transportation) that might be suitable for transportation orders with tight due dates $[11,13,61]$. Such a network of the road-rail intermodal transportation system is getting more and more attention from transportation planning field, e.g., Sun et al. [11], Uddin and Huynh [13], and Sun et al. [61].

(2) Road transportation is considered time flexible [12], which means that loading containers on trucks can be immediately conducted when the containers get unloaded and unloading containers can be immediately started once the trucks arrive at the nodes. However, rail transportation, i.e., container trains, should follow fixed departure times [18, 36, 48, 52]. That is to say, when the containers get loaded on trains, the trains should wait until the fixed departure times and then depart from the current nodes. As a result, if containers are planned to be moved by a container train, the time when they are loaded on the selected train should not be later than the fixed departure time of the train.

(3) The full-truck-load strategy is utilized by the roadrail intermodal transportation system that is associated with bulk transportation. Moreover, in the prehaul, end haul, and all-road transportation lines, there might exist more than one truck fleet. As explained by Sun et al. [31], all the truck fleets in one road transportation line can be combined into one truck fleet group under the coordination of the intermodal transportation operators. As a result, under 
the full-truck-load strategy, one road transportation line has one truck fleet group in which the trucks can be flexibly assigned into several fleets to carry containers from various transportation orders. Container trains are operated periodically [12]. The same container trains in different periods are indexed as different transportation in the modeling, so that the dimensions of associated parameters and decision variables can be reduced $[12,31]$.

\section{Fuzzy Goal Programming Model}

In this section, a multiobjective fuzzy mixed integer nonlinear programming model is established to formulate the green and reliable freight routing problem in the roadrail intermodal transportation network with multiple sources of uncertainty that are addressed by fuzzy set theory.

4.1. Assumptions. The following assumptions should be followed by the modeling in this study in order to make the optimization model rigorous.

Assumption 1. All the transportation orders that are served by the road-rail intermodal routing are known and deterministic, especially the demand for the containers of a transportation order is deterministic since this study only considers uncertainty from the road-rail intermodal transportation network.

Assumption 2. Containers of a transportation order start to get loaded at the corresponding release time at the origin.
After loading the containers at the destination is accomplished, the transportation of containers by prehaul or allroad transportation carried out by trucks immediately starts.

Assumption 3. A transportation order is considered accomplished when its containers arrive and then get unloaded at the destination.

Assumption 4. It is not allowed that containers of a transportation order are moved through the road-rail intermodal transportation network in a splittable way, so that the integrality of each transportation order is ensured and the customers can receive all the containers that they need at the same time.

Assumption 5. Early and late deliveries of the containers lead to a penalty in order to improve the timeliness of the deliveries for the sake of on-time transportation.

4.2. Notations. The symbols used in the optimization model and their representations are presented in Tables 2 and 3. It should be noted that the two kinds of decision variables are also fuzzy since they are related to the fuzzy parameters shown in Table 2 in computation.

4.3. Multiobjective Fuzzy Mixed Integer Nonlinear Programming Model. The proposed optimization model for the specific road-rail intermodal routing problem is shown as follows:

$$
\begin{aligned}
\operatorname{minimize} & \sum_{p \in P} \sum_{(i, j) \in A} \sum_{n \in T_{i j}} c_{n} \cdot q_{p} \cdot d_{i j n} \cdot x_{i j n}^{p}+\sum_{p \in P} \sum_{i \in N}\left(\sum_{h \in N_{i}^{-}} \sum_{m \in T_{h i}} e_{m} \cdot q_{p} \cdot x_{h i m}^{p}+\sum_{j \in N_{i}^{+}} \sum_{n \in T_{i j}} e_{n} \cdot q_{p} \cdot x_{i j n}^{p}\right) \\
& +\sum_{p \in P} \sum_{(i, j) \in A} \sum_{n \in \mathrm{TR}_{i j}} g \cdot q_{p} \cdot \widetilde{z}_{i j n}^{p}+\sum_{p \in P} \operatorname{pen} \cdot q_{p} \cdot\left(\max \left\{\operatorname{due}_{p}-\tilde{y}_{d_{p}}^{p}, 0\right\}+\max \left\{\widetilde{y}_{d_{p}}^{p}-\mathrm{due}_{p}, 0\right\}\right),
\end{aligned}
$$

minimize

$$
\sum_{p \in P} \sum_{(i, j) \in A} \sum_{n \in T_{i j}} \mathrm{em}_{n} \cdot q_{p} \cdot d_{i j n} \cdot x_{i j n}^{p},
$$

Equation (4) is the economic objective that aims at minimizing the total costs paid for accomplishing all the transportation orders served by the routing. It contains four formulas that are defined as follows:

Formula $\sum_{p \in P} \sum_{(i, j) \in A} \sum_{n \in T_{i j}} c_{n} \cdot q_{p} \cdot d_{i j n} \cdot x_{i j n}^{p}$ is the travel costs for moving containers from one node to another on transportation arcs.

Formula $\sum_{p \in P} \sum_{i \in N}\left(\sum_{h \in N_{i}^{-}} \sum_{m \in T_{h i}} e_{m} \cdot q_{p} \cdot x_{h i m}^{p}+\sum_{j \in N_{i}^{+}}\right.$ $\left.\sum_{n \in T_{i j}} e_{n} \cdot q_{p} \cdot x_{i j n}^{p}\right)$ represents the operational costs for loading and unloading operations at origins and destinations, as well as rail terminals where transshipment between rail and road services is realized.
Formula $\sum_{p \in P} \sum_{(i, j) \in A} \sum_{n \in \mathrm{TR}_{i j}} g \cdot q_{p} \cdot \widetilde{z}_{i j n}^{p}$ denotes the storage costs for storing containers at rail terminals before they are further moved by successive container trains.

Formula $\quad \sum_{p \in P}$ pen $\cdot q_{p} \cdot\left(\max \left\{\right.\right.$ due $\left._{p}-\tilde{y}_{d_{p}}^{p}, 0\right\}+$ $\max \left\{\tilde{y}_{d_{p}}^{p}-\right.$ due $\left.\left._{p}, 0\right\}\right)$ is the penalty costs caused by deliveries of containers at destinations that are earlier or later than the due dates claimed by customers.

Equation (5) is the environmental objective that considers the minimization of all the carbon dioxide emissions for accomplishing all the transportation orders. The calculation of the emissions is based on the activity-based method [11, 31]. 
TABle 2: Sets, indexes, and parameters.

\begin{tabular}{|c|c|}
\hline$P$ & Transportation order set served by the road-rail intermodal routing. \\
\hline$p$ & Index of a transportation order and $p \in P$. \\
\hline$o_{p}$ & Index of the origin of the containers of transportation order $p$. \\
\hline$d_{p}$ & Index of the destination of the containers of transportation order $p$. \\
\hline$q_{p}$ & Demand in TEU for the containers of transportation order $p$. \\
\hline$t_{p}^{0}$ & Release time of the containers of transportation order $p$ at origin $o_{p}$. \\
\hline due $_{p}$ & Due date of accomplishing transportation order $p$ \\
\hline$N^{P}$ & Node set of the road-rail intermodal transportation network. \\
\hline$A$ & Directed arc set of the road-rail intermodal transportation network. \\
\hline$T$ & Transportation service set of the road-rail intermodal transportation network. \\
\hline$h, i, j$ & Indexes of the nodes in the road-rail intermodal transportation network and $h, i, j \in N$. \\
\hline$N_{i}^{-}$ & Predecessor node set to node $i$ and $N_{i}^{-} \subseteq N$. \\
\hline$N_{i}^{+}$ & Successor node set to node $i$ and $N_{i}^{+} \subseteq N$. \\
\hline$(i, j)$ & Directed arc from node $i$ to node $j$ and $(i, j) \in A$. \\
\hline$T_{i j}$ & Transportation service set on $\operatorname{arc}(i, j)$ and $T_{i j} \subseteq T$. \\
\hline $\mathrm{TK}_{i j}$ & Truck service set on $\operatorname{arc}(i, j)$ and $\mathrm{TK}_{i j} \subseteq T_{i j}$ \\
\hline $\mathrm{TN}_{i j}$ & Train service set $(i, j)$ and $\mathrm{TN}_{i j} \subseteq T_{i j}$. \\
\hline$m, n$ & Indexes of transportation services in the road-rail intermodal transportation network and $m, n \in T$. \\
\hline$d_{i j n}$ & Distance in $\mathrm{km}$ of transportation service $n$ on $\operatorname{arc}(i, j)$ \\
\hline$\tilde{\mathrm{tt}}_{i j n}$ & Travel time in hour of transportation service $n$ on $\operatorname{arc}(i, j)$ and $\tilde{\mathrm{tt}}_{i j n}=\left(\mathrm{tt}_{i j n}^{1}, \mathrm{tt}_{i j n}^{2}, \mathrm{tt}_{i j n}^{3}\right)$. \\
\hline$\tilde{r}_{i j n}$ & Fuzzy capacity in TEU of transportation service $n$ on $\operatorname{arc}(i, j)$ and $\widetilde{r}_{i j n}=\left(r_{i j n}^{1}, r_{i j n}^{2}, r_{i j n}^{3}\right)$. \\
\hline$\tilde{\mathrm{ot}}_{i}^{n}$ & $\begin{array}{l}\text { Separate fuzzy loading and unloading operation time in hour per TEU of transportation service } n \text { at node } i \text { and } \\
\qquad \widetilde{\mathrm{ot}}_{i}^{n}=\left(\mathrm{ot}_{1 i}^{n}, \mathrm{ot}_{2 i}^{n}, \mathrm{ot}_{3 i}^{n}\right) .\end{array}$ \\
\hline$\tilde{f}_{i}^{n}$ & Fuzzy fixed departure time of train service $n$ from node $i$ and $\tilde{f}_{i}^{n}=\left(f_{1 i}^{n}, f_{2 i}^{n}, f_{3 i}^{n}\right)$ \\
\hline$c_{n}$ & Travel costs in CNY per TEU per km of transportation service $n$. \\
\hline$e_{n}$ & Separate loading and unloading costs in CNY per TEU of transportation service $n$. \\
\hline$g$ & Storage costs in CNY per TEU per hour of railway service. \\
\hline $\mathrm{em}_{n}$ & Carbon dioxide emission factor in $\mathrm{kg}$ per TEU per $\mathrm{km}$ of transportation service $n$. \\
\hline pen & Penalty costs in CNY per TEU per hour caused by early or late delivery. \\
\hline$M$ & A large enough positive number. \\
\hline$\pi$ & An index used in the calculation of the fuzzy decision variables and $\pi \in\{1,2,3\}$. \\
\hline
\end{tabular}

TABle 3: Decision variables.

\begin{tabular}{|c|c|}
\hline$x_{i j n}^{p}$ & $\begin{array}{l}\text { 0-1 decision variable: if transportation service } n \text { is used to move containers of transportation order } p \text { on } \operatorname{arc}(i, j), x_{i j n}^{p}=1 ; \text { otherwise, } \\
\qquad x_{i j n}^{p}=0\end{array}$ \\
\hline$\tilde{y}_{i}^{p}$ & $\begin{array}{l}\text { Non-negative fuzzy decision variable that represents the time when the containers of transportation order } p \text { arrive at node } i \text { and get } \\
\text { unloaded and } \tilde{y}_{i}^{p}=\left(y_{1 i}^{p}, y_{2 i}^{p}, y_{3 i}^{p}\right)\end{array}$ \\
\hline$\tilde{z}_{i j n}^{p}$ & $\begin{array}{l}\text { Non-negative fuzzy decision variable that represents the storage time in hour of container of transportation order } p \text { at node } i \text { before } \\
\text { being moved on } \operatorname{arc}(i, j) \text { by train service } n \text { and } \widetilde{z}_{i j n}^{p}=\left(z_{i j n}^{1 p}, z_{i j n}^{2 p}, z_{i j n}^{3 p}\right)\end{array}$ \\
\hline
\end{tabular}

$$
\begin{aligned}
& \sum_{h \in N_{i}^{-}} \sum_{m \in T_{h i}} x_{h i m}^{p}-\sum_{j \in N_{i}^{+}} \sum_{n \in T_{i j}} x_{i j n}^{p}=0, \quad \forall i \in N /\left\{o_{p}, d_{p}\right\}, \forall p \in P, \\
& \sum_{h \in N_{i}^{-}} \sum_{m \in T_{h i}} x_{h i m}^{p}-\sum_{j \in N_{i}^{+}} \sum_{n \in T_{i j}} x_{i j n}^{p}=-1, \quad i \in\left\{o_{p}\right\}, \forall p \in P \\
& \quad \sum_{h \in N_{i}^{-}} \sum_{m \in T_{h i}} x_{h i m}^{p}-\sum_{j \in N_{i}^{+}} \sum_{n \in T_{i j}} x_{i j n}^{p}=1, \quad i \in\left\{d_{p}\right\}, \forall p \in P \\
& \sum_{n \in T_{i j}} x_{i j n}^{p} \leq 1, \quad \forall(i, j) \in A, \forall p \in P, \\
& \quad y_{\pi o_{p}}^{p}=t_{p}^{0}, \quad \forall p \in P, \forall \pi \in\{1,2,3\}, \\
& \left(y_{\pi i}^{p}+\mathrm{ot}_{\pi i}^{n} \cdot q_{p}+\mathrm{tt}_{i j n}^{\pi}+\mathrm{ot}_{\pi j}^{n} \cdot q_{p}-y_{\pi j}^{p}\right) \cdot x_{i j n}^{p}=0, \quad \forall p \in P, \forall(i, j) \in A, \forall n \in \mathrm{TK}_{i j}, \forall \pi \in\{1,2,3\}
\end{aligned}
$$




$$
\begin{aligned}
& \left(f_{\pi i}^{n}+\mathrm{tt}_{i j n}^{\pi}+\mathrm{ot}_{\pi j}^{n} \cdot q_{p}-y_{\pi j}^{p}\right) \cdot x_{i j n}^{p}=0, \quad \forall p \in P, \forall(i, j) \in A, \forall n \in \mathrm{TN}_{i j}, \forall \pi \in\{1,2,3\}, \\
& \tilde{y}_{i}^{p}=\left(y_{1 i}^{p}, y_{2 i}^{p}, y_{3 i}^{p}\right), \quad \forall i \in N, \forall p \in P, \\
& \left(f_{\pi i}^{n}-y_{(4-\pi) i}^{p}-\mathrm{ot}_{(4-\pi) i}^{n} \cdot q_{p}-z_{i j n}^{\pi p}\right) \cdot x_{i j n}^{p}=0, \quad \forall p \in P, \forall(i, j) \in A, \forall n \in \mathrm{TN}_{i j}, \forall \pi \in\{1,2,3\}, \\
& \tilde{z}_{i j n}^{p}=\left(z_{i j n}^{1 p}, z_{i j n}^{2 p}, z_{i j n}^{3 p}\right), \quad \forall p \in P, \forall(i, j) \in A, \forall n \in \mathrm{TN}_{i j}, \\
& \tilde{y}_{i}^{p}+\widetilde{o t}_{i}^{n} \cdot q_{p} \leq \tilde{f}_{i}^{n} \cdot x_{i j n}^{p}+M \cdot\left(1-x_{i j n}^{p}\right), \quad \forall p \in P, \forall(i, j) \in A, \forall n \in \mathrm{TN}_{i j}, \\
& \sum_{p \in P} q_{p} \cdot x_{i j n}^{p} \leq \widetilde{r}_{i j n}, \quad \forall(i, j) \in A, \forall n \in T_{i j}, \\
& x_{i j n}^{p} \in\{0,1\}, \quad \forall p \in P, \forall(i, j) \in A, \forall n \in T_{i j}, \\
& y_{1 i}^{p} \geq y_{2 i}^{p} \geq y_{3 i}^{p} \geq 0, \quad \forall i \in N, \forall p \in P, \\
& z_{i j n}^{1 p} \geq z_{i j n}^{2 p} \geq z_{i j n}^{3 p} \geq 0, \quad \forall p \in P, \forall(i, j) \in A, \forall n \in \mathrm{TN}_{i j} .
\end{aligned}
$$

The constraint set of the optimization model includes equations (6)-(20). Their representations are explained as follows.

Equations (6) to (8) is the flow conservation constraints that ensure that an origin-to-destination route can be generated for each transportation order.

Equation (9) is the transportation order integrity constraint that ensures that the containers of a transportation order should not be splittable, which matches Assumption 5.

Equation (10) is the constraint that ensures that containers of a transportation order can start to get loaded at their release time, which represents Assumption 2.

Equations (11) to (13) are the constraints that are used to calculate fuzzy decision variable $\tilde{y}_{i}^{p}$ by firstly obtaining its three prominent points.

Equations (14) and (15) are the constraints that calculate fuzzy decision variable $\widetilde{z}_{i j n}^{p}$ in the way that is the same to the determination of $\widetilde{y}_{i}^{p}$.

Equation (16) is the fixed departure time constraint that ensures that the loading operation of containers on the selected container train should not be accomplished later than its fixed departure time.

Equation (17) is the capacity constraint that ensures that all the containers loaded on one transportation service should not exceed its capacity.

Equations (18) to (20) are the variable domain constraints that ensure that the values of the decision variables should strictly follow their definitions.

4.4. Characteristics of the Proposed Model. The proposed model is a multiobjective fuzzy mixed integer nonlinear programming model. It cannot be straightforwardly solved to provide decision makers with crisp solutions that can support decision-making since its economic objective and constraints contain both fuzzy parameters and fuzzy decision variables. Thus, the model is not clearly defined. Defuzzification should be first of all realized to obtain a crisp reformulation that is equivalent to the initial fuzzy programming model.

The reformulation is nonlinear since its economic objective has maximum function and constraints are involved with multiplications of decision variables. It is widely acknowledged that using mathematical programming software to run an exact solution algorithm is an effective way to solve the routing problem by getting its global optimum solutions [62]. Furthermore, the linear programming model is most suitable for this method. Therefore, after the defuzzification, linearization should be undertaken to generate an equivalent model that is both crisp and linear.

Moreover, the model yields two different objectives and usually has Pareto solutions (also known as nondominated solutions). One way to obtain the Pareto solutions to the routing problem is to transfer the two objectives into one objective. Based on the characteristics above, this study designs a solution approach given in Section 5 .

\section{Exact Solution Approach}

In this section, based on the analysis of the characteristics of the model presented in Section 4.4, an exact solution approach is developed as follows.

5.1. Defuzzification. The fuzzy nonlinear programming model proposed in Section 4.3 cannot be solved straightforwardly to provide the decision maker with a crisp road-rail intermodal transportation plan. Therefore, defuzzification should be first of all undertaken to generate a crisp nonlinear 
programming model that can be further processed to make it more solvable.

5.1.1. Defuzzification of the Fuzzy Objective. The proposed fuzzy programming model yields a fuzzy objective that contains fuzzy decision variables $\widetilde{z}_{i j n}^{p}$ and $\tilde{y}_{d_{p}}^{p}$. In this study, the author adoptsthe widely used fuzzy expected value model to realize the defuzzification of the fuzzy objective.
The fuzzy expected value model aims to minimize or maximize the expected value of the fuzzy objective [1].

The fuzzy expected value of the fuzzy objective shown as equation (4) is as equation (21) where $E\left[\widetilde{z}_{i j n}^{p}\right]$ and $E\left[\tilde{y}_{d_{p}}^{p}\right]$ are the fuzzy expected values of the associated fuzzy decision variables. For a given triangular fuzzy number $\tilde{a}$, there is $E[\tilde{a}]=\left(a_{1}+2 \cdot a_{2}+a_{3}\right) / 4$ [2]. Consequently, equation (21) can be written as equation (22) that is a crisp linear function.

$$
\begin{aligned}
& \operatorname{minimize} \sum_{p \in P} \sum_{(i, j) \in A} \sum_{n \in T_{i j}} c_{n} \cdot q_{p} \cdot d_{i j n} \cdot x_{i j n}^{p}+\sum_{p \in P} \sum_{i \in N}\left(\sum_{h \in N_{i}^{-}} \sum_{m \in T_{h i}} e_{m} \cdot q_{p} \cdot x_{h i m}^{p}+\sum_{j \in N_{i}^{+}} \sum_{n \in T_{i j}} e_{n} \cdot q_{p} \cdot x_{i j n}^{p}\right) \\
& +\sum_{p \in P} \sum_{(i, j) \in A} \sum_{n \in \mathrm{TR}_{i j}} g \cdot q_{p} \cdot E\left[\widetilde{z}_{i j n}^{p}\right]+\sum_{p \in P} \operatorname{pen} \cdot q_{p} \cdot\left(\max \left\{\text { due }_{p}-E\left[\tilde{y}_{d_{p}}^{p}\right], 0\right\}+\max \left\{E\left[\tilde{y}_{d_{p}}^{p}\right]-\text { due }_{p}, 0\right\}\right), \\
& \operatorname{minimize} \sum_{p \in P} \sum_{(i, j) \in A} \sum_{n \in T_{i j}} c_{n} \cdot q_{p} \cdot d_{i j n} \cdot x_{i j n}^{p}+\sum_{p \in P} \sum_{i \in N}\left(\sum_{h \in N_{i}^{-}} \sum_{m \in T_{h i}} e_{m} \cdot q_{p} \cdot x_{h i m}^{p}+\sum_{j \in N_{i}^{+}} \sum_{n \in T_{i j}} e_{n} \cdot q_{p} \cdot x_{i j n}^{p}\right) \\
& +\sum_{p \in P} \sum_{(i, j) \in A} \sum_{n \in \mathrm{TR}_{i j}} g \cdot q_{p} \cdot \frac{z_{i j n}^{1 p}+2 \cdot z_{i j n}^{2 p}+z_{i j n}^{3 p}}{4}+\sum_{p \in P} p e n \cdot q_{p} \cdot\left(\max \left\{\mathrm{due}_{p}-\frac{y_{1 d_{p}}^{p}+2 \cdot y_{2 d_{p}}^{p}+y_{3 d_{p}}^{p}}{4}, 0\right\}\right. \\
& \left.+\max \left\{\frac{y_{1 d_{p}}^{p}+2 \cdot y_{2 d_{p}}^{p}+y_{3 d_{p}}^{p}}{4}-\text { due }_{p}, 0\right\}\right)
\end{aligned}
$$

5.1.2. Defuzzification of the Fuzzy Constraints. The fuzzy programming model contains three fuzzy constraints, including equation (16) (fixed departure time constraint) and equation (17) (capacity constraint) since they involve either fuzzy parameters or fuzzy decision variables. Their existence also makes the model impossible to be solved. As a result, after undertaking the defuzzification of the fuzzy objective, it is necessary to generate the crisp reformulations of these fuzzy constraints.

Currently, fuzzy chance-constrained programming is widely acknowledged to be an effective way to deal with the fuzzy constraint and shows good feasibility $[1,2]$. Thus, this study takes advantage of this method to address the abovementioned fuzzy constraints.

Three fuzzy measures can be used to establish the fuzzy chance constraint, i.e., fuzzy possibility, necessity, and credibility measures [59]. Among the three measures, only the fuzzy credibility measure is self-dual, which means that such measure can ensure a fuzzy event must hold when its credibility reaches up to 1 , while must fail when $0[30,59]$. The other measures, however, lack such property. A fuzzy event might still fail when its possibility is 1 and hold when its necessity equals 0 .

Considering the self-duality property of the fuzzy credibility measure, this study utilizes fuzzy credibilistic chanceconstrained programming to take care of the fuzzy constraints.

The fuzzy credibilistic chance constraints of equations (16) and (17) are as following equations (23) and (24), respectively, where $\mathrm{Cr}\{\}$ is the credibility that a fuzzy event in \{\} happens and $\lambda \in[0,1.0]$ is the credibility level that is set subjectively by decision makers based on their preference:

$$
\begin{array}{r}
\operatorname{Cr}\left\{\tilde{y}_{i}^{p}+\tilde{\mathrm{ot}}_{i}^{n} \cdot q_{p} \leq \tilde{f}_{i}^{n} \cdot x_{i j n}^{p}+M \cdot\left(1-x_{i j n}^{p}\right)\right\} \geq \lambda, \\
\forall p \in P, \forall(i, j) \in A, \forall n \in \mathrm{TN}_{i j}, \\
\operatorname{Cr}\left\{\sum_{p \in P} q_{p} \cdot x_{i j n}^{p} \leq \widetilde{r}_{i j n}\right\} \geq \lambda, \quad \forall(i, j) \in A, \forall n \in T_{i j} .
\end{array}
$$

Although the fuzzy credibility chance constraints have been constructed, they still cannot be programmed and solved directly by mathematical programming software. Therefore, further crisp reformulations on them are needed. A deterministic number $a$ and a triangular fuzzy number $\tilde{n}$ have a relationship shown as the following equation $[2,59]$ :

$$
\operatorname{Cr}\{\tilde{n} \geq a\}= \begin{cases}1, & \text { if } a \leq n_{1}, \\ \frac{2 n_{2}-n_{1}-a}{2\left(n_{2}-n_{1}\right)}, & \text { if } n_{1} \leq a \leq n_{2}, \\ \frac{n_{3}-a}{2\left(n_{3}-n_{2}\right)}, & \text { if } n_{2} \leq a \leq n_{3}, \\ 0, & \text { if } a \geq n_{3} .\end{cases}
$$


Based on equation (25), $\operatorname{Cr}\{\widetilde{n} \geq a\} \geq \lambda$ can be further rewritten as equations (26) and (27) $[1,2]$ :

$$
\begin{aligned}
& 2 \lambda \cdot n_{2}-(2 \lambda-1) \cdot n_{3} \geq a, \quad \text { if } \lambda \in[0,0.5], \\
& 2(1-\lambda) \cdot n_{2}+(2 \lambda-1) \cdot n_{1} \geq a, \quad \text { if } \lambda \in(0.5,1.0] .
\end{aligned}
$$

In equation (23), the left-hand formula $\operatorname{Cr}\left[\tilde{y}_{i}^{p}+\widetilde{\operatorname{ot}}_{i}^{n} \cdot q_{p} \leq \tilde{f}_{i}^{n} \cdot x_{i j n}^{p}+M \cdot\left(1-x_{i j n}^{p}\right)\right] \geq \lambda \quad$ can be modified into $\operatorname{Cr}\left[\tilde{f}_{i}^{n} \cdot x_{i j n}^{p}-\tilde{y}_{i}^{p}-\tilde{\mathrm{ot}}_{i}^{n^{n}} \cdot q_{p} \geq M \cdot\left(x_{i j n}^{p}-1\right)\right]$ that corresponds to $\operatorname{Cr}\{\tilde{n} \geq a\}$. Accordingly, equation (23) can be reformulated as equations (28) and (29). Equation (24) can be directly converted into equations (30) and (31):

$$
\begin{array}{r}
\begin{array}{r}
2 \lambda \cdot\left(f_{2 i}^{n} \cdot x_{i j n}^{p}-y_{2 i}^{p}-\mathrm{ot}_{2 i}^{n} \cdot q_{p}\right)-(2 \lambda-1) \cdot\left(f_{3 i}^{n} \cdot x_{i j n}^{p}-y_{1 i}^{p}-\mathrm{ot}_{1 i}^{n} \cdot q_{p}\right) \geq M \cdot\left(x_{i j n}^{p}-1\right), \\
\forall p \in P, \forall(i, j) \in A, \forall n \in \mathrm{TN}_{i j}, \text { if } \lambda \in[0,0.5],
\end{array} \\
\begin{array}{r}
2(1-\lambda) \cdot\left(f_{2 i}^{n} \cdot x_{i j n}^{p}-y_{2 i}^{p}-\mathrm{ot}_{2 i}^{n} \cdot q_{p}\right)+(2 \lambda-1) \cdot\left(f_{1 i}^{n} \cdot x_{i j n}^{p}-y_{3 i}^{p}-\mathrm{ot}_{3 i}^{n} \cdot q_{p}\right) \geq M \cdot\left(x_{i j n}^{p}-1\right) \\
\forall p \in P, \forall(i, j) \in A, \forall n \in \mathrm{TN}_{i j}, \text { if } \lambda \in(0.5,1.0],
\end{array} \\
\begin{array}{r}
2 \lambda \cdot r_{i j n}^{2}-(2 \lambda-1) \cdot r_{i j n}^{3} \geq \sum_{p \in P} q_{p} \cdot x_{i j n}^{p}, \quad \forall(i, j) \in A, \forall n \in T_{i j}, \text { if } \lambda \in[0,0.5], \\
2(1-\lambda) \cdot r_{i j n}^{2}+(2 \lambda-1) \cdot r_{i j n}^{1} \geq \sum_{p \in P} q_{p} \cdot x_{i j n}^{p}, \quad \forall(i, j) \in A, \forall n \in T_{i j}, \text { if } \lambda \in(0.5,1.0] .
\end{array}
\end{array}
$$

5.2. Linearization. After the defuzzification, we can obtain a crisp mixed integer nonlinear programming model for the specific routing problem discussed in this study. The objective functions of this model are equations (22) and (5). Its constraint set contains equations (6) to (12) and (14), equations (18) to (20), and equations (28) to (31). Among these equations, equations (11), (14), and (16) are nonlinear constraints and equation (22) is a nonlinear objective.

Exact solution algorithms, e.g., branch-and-bound algorithm, are useful tools to solve the optimization problems by providing global optimum solutions. Furthermore, exact solution algorithms can be easily programmed and run by sophisticated standard mathematical programming software, e.g., LINGO. However, the exact solution algorithm is most suitable for solving the linear programming model [63]. If a nonlinear programming model describes the problem, solutions to the problem generated by an exact solution algorithm might fall into local optimum. Moreover, the computation would consume a significant amount of time, which significantly reduces the computational efficiency.

Consequently, after defuzzification, linear reformulation of the crisp mixed integer nonlinear programming model should be conducted in order to enable the routing problem to be effectively solved by using exact solution algorithms to obtain its global optimum solution with the help of mathematical programming software.

Sun and Lang [12] proposed the linearization techniques that can generate equivalent linear functions to nonlinear constraints of the mixed integer nonlinear programming model indicated at the beginning of this section. Based on the linearization techniques proposed by Sun and Lang [12], equations (11), (14), and (16) can be replaced by their equivalent linear representations shown as equations (32) to (37):

$$
\begin{array}{r}
y_{\pi i}^{p}+\mathrm{ot}_{\pi i}^{n} \cdot q_{p}+\mathrm{tt}_{i j n}^{\pi}+\mathrm{ot}_{\pi j}^{n} \cdot q_{p}-y_{\pi j}^{p} \geq M \cdot\left(x_{i j n}^{p}-1\right), \quad \forall p \in P, \forall(i, j) \in A, \forall n \in \mathrm{TK}_{i j}, \forall \pi \in\{1,2,3\}, \\
y_{\pi i}^{p}+\mathrm{ot}_{\pi i}^{n} \cdot q_{p}+\mathrm{tt}_{i j n}^{\pi}+\mathrm{ot}_{\pi j}^{n} \cdot q_{p}-y_{\pi j}^{p} \leq M \cdot\left(1-x_{i j n}^{p}\right), \quad \forall p \in P, \forall(i, j) \in A, \forall n \in \mathrm{TK}_{i j}, \forall \pi \in\{1,2,3\}, \\
f_{\pi i}^{n}+\mathrm{tt}_{i j n}^{\pi}+\mathrm{ot}_{\pi j}^{n} \cdot q_{p}-y_{\pi j}^{p} \geq M \cdot\left(x_{i j n}^{p}-1\right), \quad \forall p \in P, \forall(i, j) \in A, \forall n \in \mathrm{TN}_{i j}, \forall \pi \in\{1,2,3\}, \\
f_{\pi i}^{n}+\mathrm{tt}_{i j n}^{\pi}+\mathrm{ot}_{\pi j}^{n} \cdot q_{p}-y_{\pi j}^{p} \leq M \cdot\left(1-x_{i j n}^{p}\right), \quad \forall p \in P, \forall(i, j) \in A, \forall n \in \mathrm{TN}_{i j}, \forall \pi \in\{1,2,3\},
\end{array}
$$




$$
\begin{gathered}
z_{i j n}^{\pi p} \geq f_{\pi i}^{n}-y_{(4-\pi) i}^{p}-\operatorname{ot}_{(4-\pi) i}^{n} \cdot q_{p}+M \cdot\left(x_{i j n}^{p}-1\right), \\
\forall p \in P, \forall(i, j) \in A, \forall n \in \mathrm{TN}_{i j}, \forall \pi \in\{1,2,3\}, \\
z_{i j n}^{\pi p} \leq M \cdot x_{i j n}^{p}, \quad \forall p \in P, \forall(i, j) \in A, \forall n \in \mathrm{TN}_{i j}, \forall \pi \in\{1,2,3\} .
\end{gathered}
$$

Sun et al. [11] design a linearization technique that can be used to linearize the nonlinear max function in the optimization objectives. As for the nonlinear objective equation (22), it can be reformulated as equation (38) by using two non-negative auxiliary decision variables and two auxiliary linear constraints including equations (39) and (41):

$$
\begin{gathered}
\operatorname{minimize} \sum_{p \in P} \sum_{(i, j) \in A} \sum_{n \in T_{i j}} c_{n} \cdot q_{p} \cdot d_{i j n} \cdot x_{i j n}^{p}+\sum_{p \in P} \sum_{i \in N}\left(\sum_{h \in N_{i}^{-}} \sum_{m \in T_{h i}} e_{m} \cdot q_{p} \cdot x_{h i m}^{p}+\sum_{j \in N_{i}^{+}} \sum_{n \in T_{i j}} e_{n} \cdot q_{p} \cdot x_{i j n}^{p}\right) \\
+\sum_{p \in P} \sum_{(i, j) \in A} \sum_{n \in \mathrm{TR}_{i j}} g_{n} \cdot q_{p} \cdot \frac{z_{i j n}^{1 p}+2 \cdot z_{i j n}^{2 p}+z_{i j n}^{3 p}}{4}+\sum_{p \in P} \text { pen } \cdot q_{p} \cdot\left(\varphi_{p}+\tau_{p}\right), \\
\varphi_{p} \geq \mathrm{due}_{p}-\frac{y_{1 d_{p}}^{p}+2 \cdot y_{2 d_{p}}^{p}+y_{3 d_{p}}^{p}}{4}, \quad \forall p \in P, \\
\varphi_{p} \geq 0, \quad \forall p \in P, \\
\tau_{p} \geq \frac{y_{1 d_{p}}^{p}+2 \cdot y_{2 d_{p}}^{p}+y_{3 d_{p}}^{p}}{4} \text { due }_{p}, \quad \forall p \in P, \\
\tau_{p} \geq 0, \quad \forall p \in P .
\end{gathered}
$$

5.3. Weighted Sum Approach. The weighted sum approach has been widely utilized by current studies to deal with the multiobjective optimizations [64]. It has been acknowledged to be the most classical approach to make tradeoffs between conflict objectives.

As a result, in this study, the weighted sum approach is employed by us to address the economic objective and environmental objective of the routing optimization. Let $\mathrm{obj}_{\text {cost }}$ and objemission separately denote the economic objective, i.e., equation (38), and environmental objective, i.e., equation (5), of the road-rail intermodal routing problem, and non-negative parameters $\omega_{1}$ and $\omega_{2}$ represent the weight distributed to the economic objective and environmental objective, respectively. By using the weighted sum approach, the new objective is as the following equation:

$$
\operatorname{minimize}\left(\omega_{1} \cdot \mathrm{obj}_{\mathrm{cost}}+\omega_{2} \cdot \mathrm{obj}_{\mathrm{emission}}\right) \text {. }
$$

Non-negative parameters $\omega_{1}$ and $\omega_{2}$ are manually set by the decision makers according to their preference to get a routing decision. For example, decision makers can set $\omega_{1}$ as 1000 while $\omega_{2}$ as 1 , which means that they attach more importance to the economic objective. However, setting $\omega_{1}$ as 1 while $\omega_{2}$ as 1000 shows that decision makers give more priority to the environmental objective. By changing the values of $\omega_{1}$ and $\omega_{2}$, Pareto solutions to the routing problem with different economic objective values and environmental objective values might be obtained.

Finally, this study can obtain a single-objective mixed integer linear programming model for the road-rail intermodal routing problem investigated by this study. Such a model consists of equation (43) as the objective and equations (6) to (10), equations (18) to (20), equations (28) to (37), and equations (39) to (42) as the constraints. Since the model is linear and yields only one optimization objective, it can be solved by the exact solution algorithm implemented by the mathematical programming software.

\section{Computational Experiment}

In this section, a numerical case is given to demonstrate the feasibility of the proposed method in dealing with the specific road-rail intermodal routing problem. Some helpful insights are also revealed based on the analysis of the numerical case.

6.1. Case Design. The road-rail intermodal transportation network in this case is shown in Figure 2 that is derived from the author's previous study [61]. In this network, there are six rail transportation lines where container trains with fixed departure times are operated periodically. Twelve road 


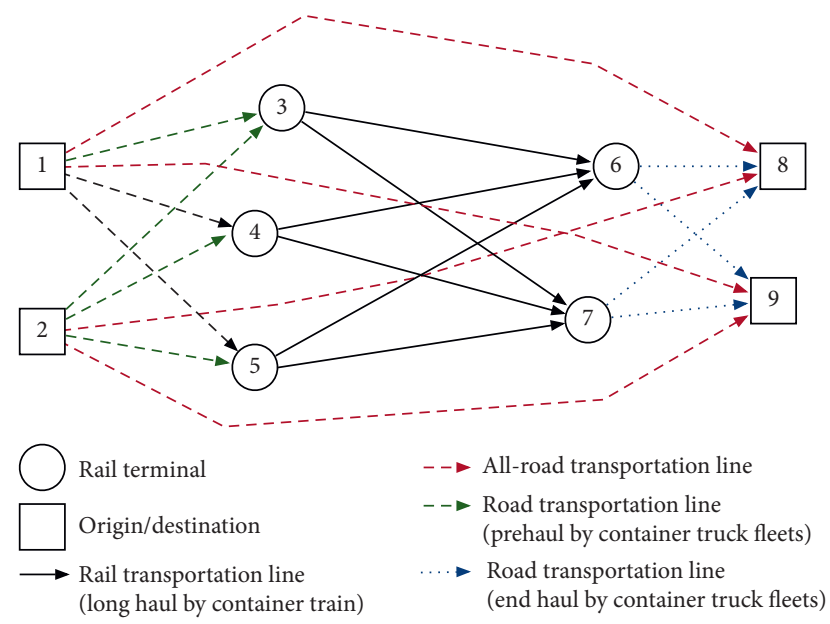

Figure 2: Road-rail intermodal transportation network in the numerical case.

transportation lines undertake prehaul and end haul, as well as all-road services for transportation orders with tight due dates.

In the road-rail transportation network, the fuzzy capacities in TEU, fuzzy travel times in hour, and travel distances in $\mathrm{km}$ of the truck fleet groups in the road transportation lines are listed in Table 4 . The information on the container trains operated in the road-rail intermodal transportation network is available in Table 5. The values of the parameters shown in Table 2 are given in Table 6 by referring to Sun et al. [11] and Sun and Li [2]. Finally, the information on the transportation orders served by the roadrail intermodal routing is provided in Table 7.

6.2. Experimental Platform. In this study, the author uses mathematical programming software LINGO version 12.0 developed by LINDO Systems Inc. to run the standard branch-and-bound algorithm to solve the specific road-rail intermodal routing problem formulated by the mixed integer linear programming model. All the computation and simulation are performed on a ThinkPad Laptop with Intel Core i5-5200U $2.20 \mathrm{GHz}$ CPU 8 GB RAM.

6.3. Computational Results. First of all, this study sets credibility level $\lambda$ as 1.0, i.e., the decision makers would not like to bear any risk that might lead to transportation failure on capacity constraint and fixed departure time constraint. Then, this study conducts a serial of calculations using different values of $\omega_{1}$ and $\omega_{2}$. As for the case presented in Section 6.1, this study sets $\omega_{1}$ as 1000 and $\omega_{2}$ as 1 to get the optimum value of the economic objective and obtain the value of the environmental objective. Meanwhile, the optimum value of the environmental objective and corresponding value of the economic objective can be also generated by setting $\omega_{1}$ as 1 and $\omega_{2}$ as 1000 . The computational results are shown in Table 8.

It can be observed from Table 8 that the two objectives cannot reach their optimum simultaneously. Consequently, there exist Pareto solutions to the numerical case. By varying the values of $\omega_{1}$ and $\omega_{2}$ according to the magnitudes of the two objectives, this study can generate the Pareto solutions illustrated in Figure 3. All the Pareto solutions can be obtained within 20 seconds using the solution approach proposed in Section 5.

As we can see from Figure 3, the economic objective and environmental objective of the road-rail intermodal routing problem are at conflict with each other. Improving either one of the objectives will worsen the other. Since the two objectives have a conflicted relationship, decision makers must make tradeoffs between them in the practical decisionmaking. The Pareto solutions illustrated in Figure 3 can help decision makers to determine the road-rail intermodal route plan that is suitable for a specific decision-making situation. As indicated by Sun and Li [2] and Wang et al. [1], multiplecriteria decision-making methods, e.g., AHP method, can be used to help decision makers to select the most suitable Pareto solutions under a given decision-making situation.

6.4. Sensitivity Analysis on Routing Optimization with respect to Network Uncertainty. After the decision makers determine the weights distributed to the two objectives, what they need to do is to determine the value of the credibility level. Credibility level reflects the decision makers' preference to the reliability of the routing optimization concerning the fixed departure time constraint, i.e., equation (23), and the capacity constraint, i.e., equation (24). In this section, the author analyzes whether and how the network uncertainty influences the road-rail intermodal routing optimization through credibility level.

The analysis in this section and the following sections all takes the road-rail intermodal routing optimization under $\omega_{1}=1$ and $\omega_{2}=150$ as an example. The abovementioned setting of weights corresponds to the sixth Pareto solution from the left side in Figure 3 when credibility level is set as 1.0 and means that decision makers give priority to the economic objective, while still paying some attention to the environmental objective. The analysis presented as follows remain the same if decision makers hold different weights.

This study varies confidence level $\lambda$ from 0.1 to 1.0 with a step size of 0.1 and calculate the optimization results corresponding to each credibility level. The sensitivity is shown in Figure 4.

Figure 4 demonstrates that transportation network uncertainty has a significant effect on the road-rail intermodal routing optimization. Different credibility level might lead to different values of both economic objective and environment objective. The routing optimization is very sensitive to the credibility level when it changes from 0.4 to 0.5 and from 0.6 to 0.7 . The increase in credibility level does not always result in constantly improved reliability of the routing optimization, which has been demonstrated by Sun et al. $[2,11,30]$. Sometimes when increasing the credibility, the reliability is not enhanced, while the objectives get worse. For example, in Figure 4, when changing the confidence level from 0.6 to 0.7 , it is not sure if the reliability of the transportation concerning the capacity constraint and fixed departure time constraint is getting better, but the economic objective that decision makers attach more importance 
TABLE 4: Information on the truck fleet groups in the road-rail intermodal transportation network.

\begin{tabular}{lccc}
\hline Road transportation lines (truck fleet groups) & Fuzzy capacities in TEU & Fuzzy travel times in hour & Travel distances in km \\
\hline$(1,3)$ & $45,50,65$ & $3.2,4.0,4.8$ & 90 \\
$(1,4)$ & $60,67,73$ & $4.2,5.0,6.3$ & 110 \\
$(1,5)$ & $55,64,70$ & $8.5,10.0,14.2$ & 200 \\
$(1,8)$ & $55,67,71$ & $14.5,18.0,23.4$ & 600 \\
$(1,9)$ & $50,54,63$ & $18.5,24.4,28.0$ & 680 \\
$(2,3)$ & $43,48,58$ & $8.5,12.2,15.5$ & 285 \\
$(2,4)$ & $48,55,60$ & $6.0,10.4,13.5$ & 210 \\
$(2,5)$ & $45,54,60$ & $4.5,5.3,6.8$ & 140 \\
$(2,8)$ & $40,55,64$ & $20.3,25.5,30.0$ & 700 \\
$(2,9)$ & $55,67,72$ & $18.5,22.0,25.3$ & 650 \\
$(6,8)$ & $55,58,64$ & $5.5,6.7,7.5$ & 140 \\
$(6,9)$ & $48,54,68$ & $3.6,4.5,5.2$ & 200 \\
$(7,8)$ & $50,60,65$ & $7.6,8.8,9.3$ & 320 \\
$(7,9)$ & $60,67,71$ & $2.5,3.0,4.5$ & 100 \\
\hline
\end{tabular}

TABLE 5: Information on the container trains in the road-rail intermodal transportation network.

\begin{tabular}{lccccc}
\hline $\begin{array}{l}\text { Rail transportation lines } \\
\text { (container trains) }\end{array}$ & $\begin{array}{c}\text { Fuzzy fixed } \\
\text { departure times }\end{array}$ & $\begin{array}{c}\text { Fuzzy capacities } \\
\text { in TEU }\end{array}$ & $\begin{array}{c}\text { Fuzzy travel times } \\
\text { in hour }\end{array}$ & $\begin{array}{c}\text { Travel distances } \\
\text { in km }\end{array}$ & $\begin{array}{c}\text { Periods in number of } \\
\text { trains per day }\end{array}$ \\
\hline$(3,6)$ & $5,6.5,7$ & $86,93,100$ & $4.5,5.2,6.0$ & 520 & 1 \\
$(3,7)$ & $7.2,8.4,9$ & $78,85,94$ & $6.2,6.8,7.5$ & 600 & 1 \\
$(4,6)$ & $14,14.6,15.3$ & $82,89,95$ & $6.5,7.4,8.2$ & 650 & 1 \\
$(4,7)$ & $11,11.6,12.5$ & $90,94,102$ & $4.6,5.0,5.6$ & 480 & 1 \\
$(5,6)$ & $15,15.3,15.8$ & $90,98,110$ & $5.8,6.4,6.8$ & 610 & 1 \\
$(5,7)$ & $9.6,10.3,10.5$ & $89,95,98$ & $6.8,7.2,7.8$ & 660 & 1 \\
\hline
\end{tabular}

TABLE 6: Values of the parameters indicated by Table 1 in the numerical case.

\begin{tabular}{lcc}
\hline Parameters & & Values \\
\hline Penalty costs in CNY per TEU per hour & 1000 & Road transportation \\
& Rail transportation & 6 \\
Travel costs in CNY per TEU per km & 2.025 & 195 \\
Separate loading and unloading costs in CNY per TEU & 3.125 & - \\
Storage costs in CNY per TEU per hour & 0.262 & 1.064 \\
Carbon dioxide emission factor in kg per TEU per km & $0.05,0.10,0.15$ & $0.10,0.20,0.25$ \\
Separate fuzzy loading and unloading time in hour per TEU &
\end{tabular}

TABLE 7: Transportation orders served by the road-rail intermodal routing optimization in the numerical case.

\begin{tabular}{lccccc}
\hline Transportation order no. & Origins & Destinations & Release times & Due dates & Demands in TEU \\
\hline 1 & 1 & 8 & 8 & 27 & 24 \\
2 & 1 & 8 & 11 & 45 & 28 \\
3 & 1 & 9 & 13 & 50 & 21 \\
4 & 1 & 9 & 2 & 30 & 23 \\
5 & 2 & 8 & 10 & 38 & 18 \\
6 & 2 & 8 & 3 & 27 & 25 \\
7 & 2 & 9 & 6 & 31 & 21 \\
8
\end{tabular}

becomes worse. As a result, it cannot be determined for sure that 0.7 as the credibility level is better than 0.6 .

6.5. Fuzzy Simulation for Identifying the Best Credibility Level. Under the above circumstance shown in Figure 4 , it is necessary to quantify the reliability of the routing optimization under different credibility levels. However, the actual reliability can be only quantified when the planned road-rail intermodal routes are used to accomplish the transportation orders in practice. However, the fact is that the routing is an advanced task that should be undertaken before the actual transportation starts [30]. We can only simulate the actual transportation by simulating the 
TABLE 8: Optimum values of the two objectives.

\begin{tabular}{lcc}
\hline & $\begin{array}{c}\text { Economic } \\
\text { objective }\end{array}$ & $\begin{array}{c}\text { Environmental } \\
\text { objective }\end{array}$ \\
\hline$\omega_{1}=1000$ and $\omega_{2}=1$ & $1787112 \mathrm{CNY}$ & $112814 \mathrm{~kg}$ \\
$\omega_{1}=1$ and $\omega_{2}=1000$ & $4637615 \mathrm{CNY}$ & $83342 \mathrm{~kg}$ \\
\hline
\end{tabular}

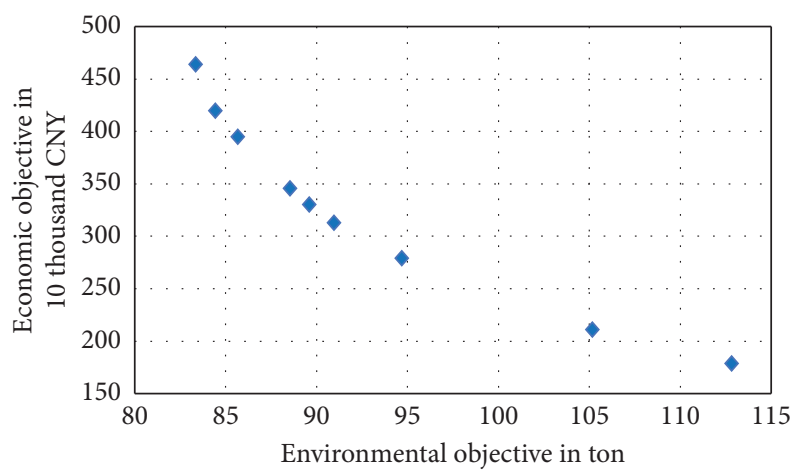

Figure 3: Pareto solutions to the road-rail intermodal routing problem when credibility level is 1.0.

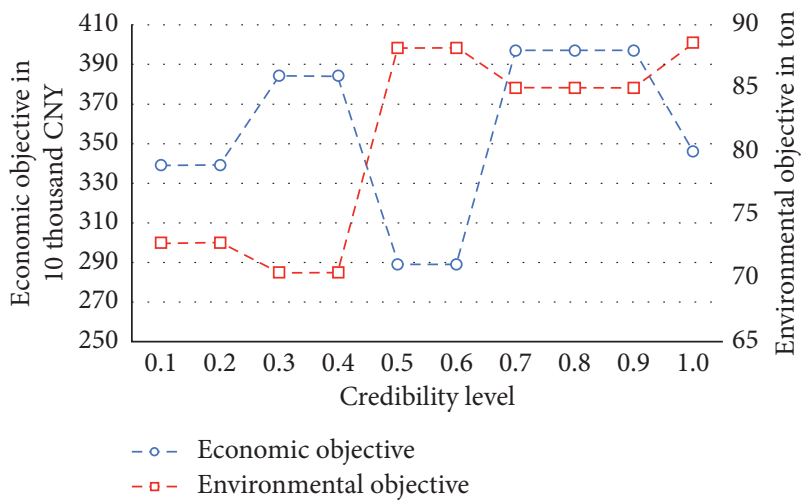

FIGURE 4: Sensitivity of the road-rail intermodal routing optimization with respect to the confidence level.

deterministic values of fuzzy parameters that can be only known when the actual transportation starts.

Fuzzy simulation developed by the previous studies of Sun et al. $[2,11,30]$ can be used to simulate the actual transportation by generating the deterministic values of fuzzy parameters of the transportation network based on their fuzzy membership function. Fuzzy simulation can be carried out several times to obtain a serial of actual transportation scenarios. Then, using these deterministic scenarios, this study can test the reliability of the planned road-rail intermodal routes with respect to the capacity constraint and fixed departure time constraint under different credibility levels in a quantitative way. The process of fuzzy simulation is shown in Figure 5.

6.5.1. Quantifying Reliability of Planned Routes under Different Credibility Levels. In this section, the author defines additional notations as follows for deterministic transportation scenarios. $y_{i}^{p}$ : non-negative deterministic decision variable that represents the time when the containers of transportation order $p$ arrive at node $i$ and get unloaded.

$z_{i j n}^{p}$ : non-negative deterministic decision variable that represents the storage time in hour of the containers of transportation order $p$ at node $i$ before being moved on arc $(i, j)$ by train service $n$.

$K$ : total times of fuzzy simulation in the numerical case. $k$ : index of a certain fuzzy simulation that corresponds to a deterministic transportation scenario and $k=1,2$, $3, \ldots, K$.

$\mathrm{tt}_{i j n}^{k}$ : deterministic travel time in hour of transportation service $n$ on $\operatorname{arc}(i, j)$ generated in the $k$ th fuzzy simulation.

$r_{i j n}^{k}$ : deterministic capacity in TEU of transportation service $n$ on $\operatorname{arc}(i, j)$ generated in the $k$ th fuzzy simulation.

$\mathrm{ot}_{i k}^{n}$ : separate deterministic fuzzy loading and unloading operation time in hour per TEU of transportation service $n$ at node in the $k$ th fuzzy simulation.

$f_{i k}^{n}$ : deterministic fixed departure time of train service $n$ from node $i$ in the $k$ th fuzzy simulation.

In the $k$ th fuzzy simulation, this study tests if the planned routes under different credibility levels satisfy the following two constraints:

$$
\begin{array}{r}
y_{i}^{p}+\mathrm{ot}_{i k}^{n} \cdot q_{p} \leq f_{i k}^{n} \cdot x_{i j n}^{p}+M \cdot\left(1-x_{i j n}^{p}\right), \\
\forall p \in P, \forall(i, j) \in A, \forall n \in \mathrm{TN}_{i j}, \\
\sum_{p \in P} q_{p} \cdot x_{i j n}^{p} \leq r_{i j n}^{k}, \quad \forall(i, j) \in A, \forall n \in T_{i j} .
\end{array}
$$

If equations (44) and (45) are both satisfied, the planned routes are considered feasible for $k$ th deterministic transportation scenario, otherwise, failed. In this study, the author runs fuzzy simulation 20 times, i.e., $K=20$, and thus generate 20 deterministic transportation scenarios. The author can then obtain the times that the planned routes under a certain credibility level are feasible or failed in the simulated deterministic scenarios. Furthermore, the author can get the ratios that the planned routes are feasible or failed in these scenarios. The results are indicated in Figure 6.

As we can see from Figure 6, with the increase in credibility level, the ratio that the planned routes are feasible improves. The improvement is stepwise. When the credibility level is set as 0.5 or 0.6 , the corresponding ratio is only $15 \%$, which is very low and means that the planned routes under such credibility level yield extensive reliability risk that the capacity constraint or fixed departure time constraint is violated. Therefore, in practical transportation, the planned routes under the credibility level of 0.5 and 0.6 will not be considered by the decision makers.

When the credibility level is changed to $0.7,0.8$, or 0.9 , the ratio that the planned routes are feasible is significantly enhanced from $15 \%$ to $75 \%$ by 3 times. In practice, the decision makers might accept such reliability to a certain 


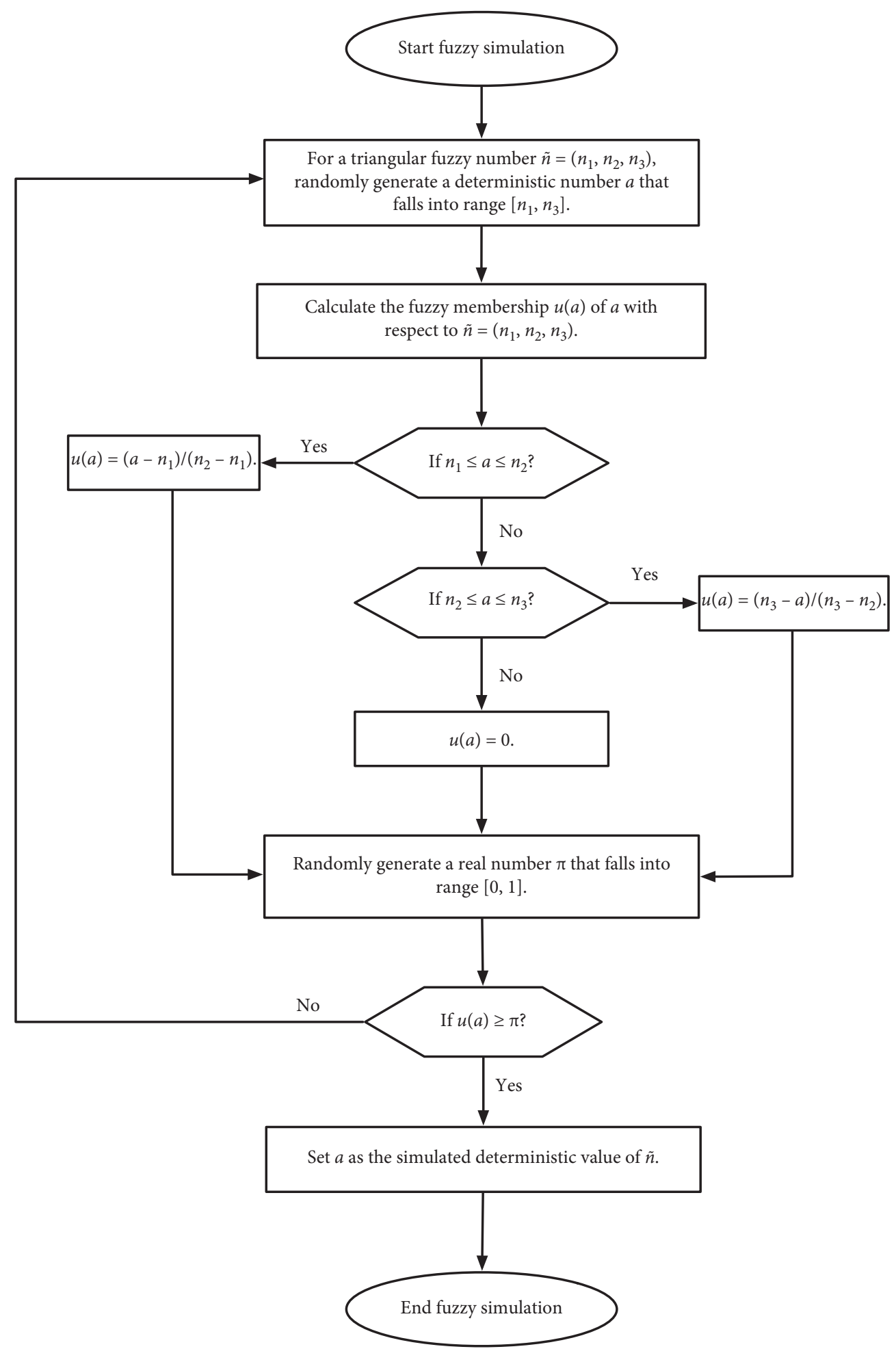

FIGURE 5: Fuzzy simulation for generating deterministic values of triangular fuzzy numbers [2, 11, 30].

degree, on condition that they would like to bear some risk. When the credibility level reaches up to 1.0 , such ratio increases to $100 \%$, which means that the planned routes under such credibility level are considerably feasible in practical transportation.
6.5.2. Quantifying Gaps between Planned Routes and Actual Best Routes. In this section, this study assumes that decision makers accept the reliability of the planned routes under the credibility level of $0.7,0.8,0.9$, or 1.0 . Since the planned routes obtained by the optimization under the credibility 


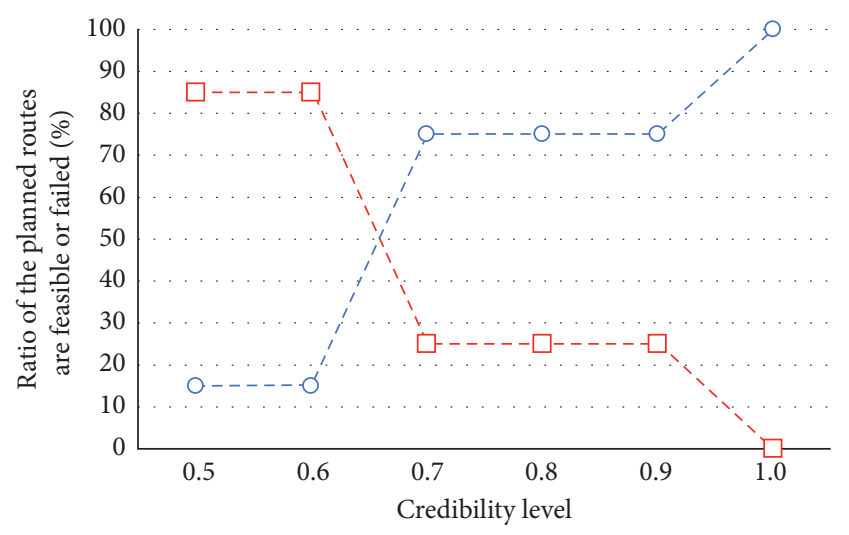

-O- Ratio that the planned routes are feasible

$-\square-$ Ratio that the planned routes are failed

FIGURE 6: Ratio of the planned routes are feasible or failed in the simulated deterministic scenarios.

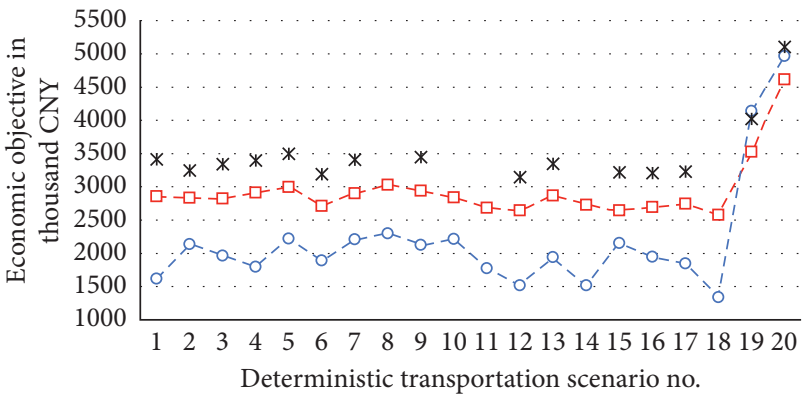

$$
\begin{aligned}
& \text {-o- Actual best routes } \\
& \text { * Planned routes under credibility level of } 0.7,0.8 \text {, or } 0.9 \\
& \text { - } \text { - Planned routes under credibility level of } 1.0
\end{aligned}
$$

Figure 7: Comparison of the economic objective between the planned routes and the actual best routes.

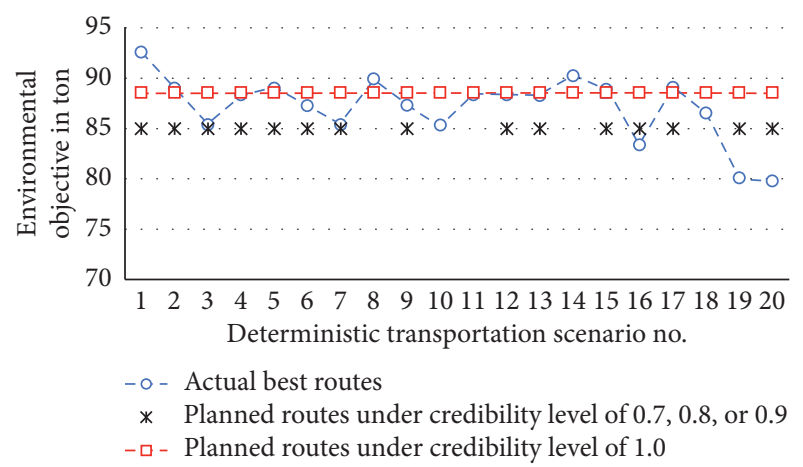

FIgURE 8: Comparison of the environmental objective between the planned routes and the actual best routes.

level of $0.7,0.8$, or 0.9 differ from these under the credibility level of 1.0, it is necessary to compare them to help decision makers to determine a crisp route plan.

Using the deterministic forms defined in Section 6.5.1 to replace the corresponding fuzzy parameters and fuzzy decision variables, this study can get a deterministic model for the routing problem in the deterministic road-rail intermodal transportation network.
For the $k$ th deterministic transportation scenario, this study can employ the deterministic model to generate its actual best routes. This study can also calculate the values of the two objectives when using the planned routes under the credibility level of $0.7,0.8,0.9$, or 1.0 to move containers in the $k$ th deterministic transportation scenario. Finally, this study can compare the objectives between the actual best routes and the planned routes. The comparisons are indicated in Figures 7 and 8. It should be noted that the planned routes under the credibility level of $0.7,0.8$, or 0.9 is not feasible in the 8 th, 10th, 11th, 14th, and 18th deterministic transportation scenarios. Thus, this study cannot obtain the values of the objectives in them.

Based on Figures 7 and 8, this study can quantify the gaps of the two objectives between the planned routes and the actual best routes. This study defines the following symbols.

$\mathrm{eco}_{k}^{\text {determinsitc }}\left(\mathrm{env}_{k}^{\text {determinsitc }}\right)$ : optimum value of the economic (environmental) objective given by the deterministic model in the $k$ th deterministic transportation scenario.

$\mathrm{eco}_{k}^{\mathrm{fuzzy}-\lambda}\left(\mathrm{env}_{k}^{\mathrm{fuzzy}-\lambda}\right)$ : value of the economic (environmental) objective when moving containers along the planned routes designed by the fuzzy programming model under credibility level $\lambda$ in the $k$ th deterministic transportation scenario.

$\mathrm{RMSE}_{\mathrm{eco}}^{\lambda}\left(\mathrm{RMSE}_{\mathrm{env}}^{\lambda}\right)$ : root mean square error of the economic (environmental) objective values when moving containers along the planned routes under credibility level $\lambda$ with respect to the corresponding optimum values given by the deterministic model in the total $K$ deterministic transportation scenarios. $\mathrm{RMSE}_{\mathrm{eco}}^{\lambda}$ and $\mathrm{RMSE}_{\text {env }}^{\lambda}$ can be calculated by equations (46) and (47):

$$
\begin{aligned}
\mathrm{RMSE}_{\mathrm{eco}}^{\lambda} & =\sqrt{\frac{\sum_{k=1}^{20}\left(\mathrm{eco}_{k}^{\mathrm{fuzzy}-\lambda}-\mathrm{eco}_{k}^{\text {determinsitc }}\right)^{2}}{K}}, \\
\mathrm{RMSE}_{\mathrm{env}}^{\lambda} & =\sqrt{\frac{\sum_{k=1}^{20}\left(\mathrm{env}_{k}^{\mathrm{fuzzy}-\lambda}-\mathrm{evn}_{k}^{\text {determinsitc }}\right)^{2}}{K}} .
\end{aligned}
$$

Using the two kinds of root mean square error defined above, this study can effectively quantify the gaps between the planned routes given by the fuzzy programming model and the actual best routes given by the deterministic model. The computational results of the root mean square error are shown in Table 9. It should be noted that the calculation of the root mean square error does not include the deterministic transportation scenarios that the planned routes under the credibility level of $0.7,0.8$, or 0.9 are infeasible, i.e., for these routes, $K$ equals 15 instead of 20 .

As shown in Table 9, when using the planned routes under the credibility level of 1.0, the root mean square errors of the economic objective and environmental objective values can decrease by $\sim 60.5 \%$ and $\sim 10.2 \%$. Consequently, 
TABLE 9: Root mean square error of the two objectives in the fuzzy simulation.

\begin{tabular}{lcc}
\hline Credibility level & Economic objective in thousand CNY & Environmental objective in ton \\
\hline $0.7,0.8$, and 0.9 & 2224.5 & 3.82 \\
1.0 & 877.7 & 3.43 \\
\hline
\end{tabular}

this study can draw the conclusion that the planned routes given by the fuzzy programming model under the credibility level of 1.0 are closer to the actual optimum situation. Together with the higher reliability over the planned routes under the credibility level of $0.7,0.8$, or 0.9 illustrated in Figure 6, the planned routes under the credibility level of 1.0 are recommended to the decision makers to consider as the crisp road-rail intermodal route plan that can be used in the practical transportation.

6.6. Comparing Proposed Fuzzy Programming Approach with Existing Deterministic Modeling. In the existing literature that focuses on the freight routing problem in the deterministic road-rail intermodal transportation network, parameters including capacities, fixed departure times, travel times, and loading/unloading times, are estimated in a deterministic way by using their most likely values. Their modeling can be easily realized by using $r_{i j \sim_{\sim}^{n}}^{2}, f_{2 i}^{n}, \mathrm{tt}_{i j n}^{2}$, and ot ${ }_{2 i}^{n}$ to take the place of $\widetilde{r}_{i j n}, \widetilde{f}_{i}^{n}, \widetilde{\mathrm{tt}}_{i j n}$, and $\widetilde{\mathrm{ot}}_{i}^{n}$ in the fuzzy programming model established in this study, respectively. Accordingly, $\widetilde{y}_{i}^{p}$ and $\widetilde{z}_{i j n}^{p}$ will be separately replaced by $y_{2 i}^{p}$ and $z_{i j n}^{2 p}$.

On the condition that $\omega_{1}=1$ and $\omega_{2}=150$, this study first uses the standard branch-and-bound algorithm to solve the deterministic road-rail intermodal routing problem on LINGO version 12.0. Then, this study also tests if the planned routes under certainty are feasible or failed in the 20 deterministic transportation scenarios simulated by using fuzzy simulation. This study can also obtain the ratio that the planned routes under road-rail intermodal transportation network certainty are feasible in all the deterministic scenarios. The ratio is only $15 \%$, which is the same as compared to the planned routes given by the fuzzy programming model under the credibility level of 0.5 or 0.6 , but is considerably lower than results of the fuzzy programming model when the credibility level is larger than 0.6 .

Additionally, the planned routes under the road-rail intermodal transportation network certainty have smaller root mean square errors of the economic objectives (i.e., 713.5 thousand CNY that decreases by $\sim 18.7 \%$ compared with the planned routes under a credibility level of 1.0), while yielding larger root mean square errors of the environmental objectives (i.e., 4.56 ton that increases by $\sim 32.9 \%$ compared with the planned routes under a credibility level of 1.0) in the three deterministic transportation scenarios that are feasible.

Above all, although the planned routes under network certainty can slightly improve the economic objective, it worsens the environmental objective and also lead to an extensive risk that the routes violate the capacity constraint and the fixed departure time constraint. As a result, this study can conclude that considering the parameters of the road-rail intermodal transportation network as uncertainty can remarkably improve reliability and thereby reduce failure risk of the associated freight routing optimization when compared with the deterministic road-rail intermodal routing optimization.

\section{Conclusions}

In this study, the author aims at modeling and solving a green and reliable road-rail intermodal routing problem. The objectives of the road-rail intermodal routing modeling include (1) minimizing total costs for accomplishing all the transportation orders served by the routing optimization; (2) minimizing total carbon dioxide emissions created in the transportation process to realize green transportation. The reliability of the routing optimization is enhanced by fully considering the uncertainty of the road-rail intermodal transportation network. Parameters that are considerably sensitive to the real-time status of the network, including capacities, fixed departure times of container trains, travel times, and loading/unloading times, are modeled as triangular fuzzy numbers based on fuzzy set theory.

To deal with the green and reliable road-rail intermodal routing problem under network uncertainty, a fuzzy goal programming approach is developed by this study. The specific routing problem is initially formulated by a multiobjective fuzzy mixed integer nonlinear programming model. Then, an exact solution approach that combines defuzzification, linearization, and weighted sum method is proposed to address the initial model to enable that the problem can be solved by the exact solution algorithm run by the mathematical programming software. In the case study, besides demonstrating the feasibility of the proposed methods, this study uses sensitivity analysis and fuzzy simulation to draw some helpful insights as follows.

(1) The economic objective is in conflict with the environmental objective, i.e., improving one objective will worsen the other one. By using the weighted sum method, the Pareto solutions to the problem can be obtained, which provides candidates for decision makers to make effective tradeoffs between the objectives and further select the road-rail intermodal routes plan that matches a particular decision-making situation.

(2) Transportation network uncertainty yields significant effects on the two objectives of the road-rail intermodal routing optimization as well as its reliability. Using fuzzy set theory to model the uncertain parameters and modeling the problem by fuzzy goal programming show good feasibility.

(3) The quality of credibility levels can be quantified by using fuzzy simulation demonstrated in our study. The best credibility level can be identified to provide 
the decision makers with the best crisp routes plan that is most suitable for practical transportation.

In the future work on this study, the author will focus on the following three aspects:

(1) Uncertainty from the side of customers, e.g., demand uncertainty [61], is not considered in this study. In the future work, a comprehensive consideration of uncertainty from both demanders (shippers and receivers) and providers (transportation network) will be investigated.

(2) Some other defuzzification methods, e.g., fuzzy ranking method [60], can be also adopted to obtain the crisp reformulation of the fuzzy programming model. The comparison among different defuzzification methods can be discussed.

(3) The potential utilization of some emerging fuzzy numbers, e.g., type-II fuzzy numbers [65], also is worth a try to check if the forms of fuzzy numbers significantly influence the optimization results of the routing problem under uncertainty.

\section{Data Availability}

The fuzzy simulation data used to support the findings of the study are included within the supplementary information file.

\section{Conflicts of Interest}

The author declares that there are no conflicts of interest regarding the publication of this paper.

\section{Acknowledgments}

This research was funded by the Shandong Provincial Natural Science Foundation of China under Grant no. ZR2019BG006, the Project for Humanities and Social Sciences Research of Ministry of Education of China under Grant no. 19YJC630149, and the Shandong Provincial Higher Educational Social Science Program of China under Grant no. J18RA053. The author would like to thank Dr. Cevin Zhang from KTH Royal Institute of Technology for his contribution to improving the writing of this paper.

\section{Supplementary Materials}

The supplementary material contains an appendix that presents the data of the fuzzy simulation results on the fuzzy parameters. These data are used for the analysis in Sections 6.5 and 6.6. (Supplementary Materials)

\section{References}

[1] R. Wang, K. Yang, L. Yang, and Z. Gao, "Modeling and optimization of a road-rail intermodal transport system under uncertain information," Engineering Applications of Artificial Intelligence, vol. 72, pp. 423-436, 2018.

[2] Y. Sun and X. Li, "Fuzzy programming approaches for modeling a customer-centred freight routing problem in the road-rail intermodal hub-and-spoke network with fuzzy soft time windows and multiple sources of time uncertainty," Mathematics, vol. 7, no. 8, p. 739, 2019.

[3] Y. Zhao, R. Liu, X. Zhang, and A. Whiteing, "A chanceconstrained stochastic approach to intermodal container routing problems," PLoS One, vol. 13, no. 2, Article ID e0192275, 2018.

[4] B. Slack, "Intermodal transportation," in Handbook of Logistics and Supply-Chain Management, pp. 141-154, Emerald Group Publishing Limited, Bingley, UK, 2008.

[5] S. Zhang, X. Ruan, Y. Xia, and X. Feng, "Foldable container in empty container repositioning in intermodal transportation network of Belt and Road Initiative: strengths and limitations," Maritime Policy \& Management, vol. 45, no. 3, pp. 351-369, 2018.

[6] Y. Kayikci, "A conceptual model for intermodal freight logistics centre location decisions," Procedia-Social and Behavioral Sciences, vol. 2, no. 3, pp. 6297-6311, 2010.

[7] D. M. Z. Islam, J. Dinwoodie, and M. Roe, "Towards supply chain integration through multimodal transport in developing economies: the case of Bangladesh," Maritime Economics \& Logistics, vol. 7, no. 4, pp. 382-399, 2005.

[8] T. G. Crainic, "Service network design in freight transportation," European Journal of Operational Research, vol. 122, no. 2, pp. 272-288, 2000.

[9] A. Caris, C. Macharis, and G. K. Janssens, "Decision support in intermodal transport: a new research agenda," Computers in Industry, vol. 64, no. 2, pp. 105-112, 2013.

[10] Y. Sun, M. Lang, and D. Wang, "Optimization models and solution algorithms for freight routing planning problem in the multi-modal transportation networks: a review of the status-of-the-art," The Open Civil Engineering Journal, vol. 9, no. 1, 2015.

[11] Y. Sun, M. Hrušovský, C. Zhang, and M. Lang, "A timedependent Fuzzy programming approach for the green multimodal routing problem with rail service capacity uncertainty and road traffic congestion," Complexity, vol. 2018, Article ID 8645793, 22 pages, 2018.

[12] Y. Sun and M. Lang, "Modeling the multicommodity multimodal routing problem with schedule-based services and carbon dioxide emission costs," Mathematical Problems in Engineering, vol. 2015, Article ID 406218, 21 pages, 2015.

[13] M. Uddin and N. Huynh, "Reliable routing of road-rail intermodal freight under uncertainty," Networks and Spatial Economics, vol. 19, no. 3, pp. 929-952, 2019.

[14] T.-S. Chang, "Best routes selection in international intermodal networks," Computers \& Operations Research, vol. 35, no. 9, pp. 2877-2891, 2008.

[15] G. Xiong and Y. Wang, "Best routes selection in multimodal networks using multi-objective genetic algorithm," Journal of Combinatorial Optimization, vol. 28, no. 3, pp. 655-673, 2014.

[16] A. Ghaderi and R. L. Burdett, "An integrated location and routing approach for transporting hazardous materials in a bimodal transportation network," Transportation Research Part E: Logistics and Transportation Review, vol. 127, pp. 49-65, 2019.

[17] M. Verma, V. Verter, and N. Zufferey, “A bi-objective model for planning and managing rail-truck intermodal transportation of hazardous materials," Transportation Research Part E: Logistics and Transportation Review, vol. 4C8, no. 1, pp. 132-149, 2012.

[18] E. Demir, M. Hrušovský, W. Jammernegg, and T. Van Woensel, "Green intermodal freight transportation: 
bi-objective modelling and analysis," International Journal of Production Research, vol. 57, no. 19, pp. 6162-6180, 2019.

[19] J. H. Cho, H. S. Kim, and H. R. Choi, "An intermodal transport network planning algorithm using dynamic programming-A case study: from Busan to Rotterdam in intermodal freight routing," Applied Intelligence, vol. 36, no. 3, pp. 529-541, 2012.

[20] J. J. Winebrake, J. J. Corbett, A. Falzarano et al., "Assessing energy, environmental, and economic tradeoffs in intermodal freight transportation," Journal of the Air \& Waste Management Association, vol. 58, no. 8, pp. 1004-1013, 2008.

[21] J. Jiang, D. Zhang, S. Li, and Y. Liu, "Multimodal green logistics network design of urban agglomeration with stochastic demand," Journal of Advanced Transportation, vol. 2019, Article ID 4165942, 19 pages, 2019.

[22] E. Demir, W. Burgholzer, M. Hrušovský, E. Arıkan, W. Jammernegg, and T. V. Woensel, "A green intermodal service network design problem with travel time uncertainty," Transportation Research Part B: Methodological, vol. 93, pp. 789-807, 2016.

[23] A. E. P. Rivera and M. R. Mes, "Integrated scheduling of drayage and long-haul operations in synchromodal transport," Flexible Services and Manufacturing Journal, vol. 31, no. 3, pp. 763-806, 2019.

[24] C.-H. Liao, P.-H. Tseng, and C.-S. Lu, "Comparing carbon dioxide emissions of trucking and intermodal container transport in Taiwan," Transportation Research Part D: Transport and Environment, vol. 14, no. 7, pp. 493-496, 2009.

[25] F. Fotuhi and N. Huynh, "A reliable multi-period intermodal freight network expansion problem," Computers \& Industrial Engineering, vol. 115, pp. 138-150, 2018.

[26] D. Ambrosino, A. Sciomachen, and C. Surace, "Evaluation of flow dependent external costs in freight logistics networks," Networks, vol. 74, no. 2, pp. 111-123, 2019.

[27] M. M. Uddin and N. Huynh, "Routing model for multicommodity freight in an intermodal network under disruptions," Transportation Research Record: Journal of the Transportation Research Board, vol. 2548, no. 1, pp. 71-80, 2016.

[28] M. Mohammadi, P. Jula, and R. Tavakkoli-Moghaddam, "Design of a reliable multi-modal multi-commodity model for hazardous materials transportation under uncertainty," European Journal of Operational Research, vol. 257, no. 3, pp. 792-809, 2017.

[29] B. Y. Chen, W. H. K. Lam, A. Sumalee, Q. Li, H. Shao, and Z. Fang, "Finding reliable shortest paths in road networks under uncertainty," Networks and Spatial Economics, vol. 13, no. 2, pp. 123-148, 2013.

[30] Y. Sun, G. Zhang, Z. Hong, and K. Dong, "How uncertain information on service capacity influences the intermodal routing decision: a fuzzy programming perspective," Information, vol. 9, no. 1, p. 24, 2018.

[31] Y. Sun, X. Li, X. Liang, and C. Zhang, "A Bi-objective fuzzy credibilistic chance-constrained Programming approach for the hazardous materials road-rail multimodal routing Problem under uncertainty and sustainability," Sustainability, vol. 11, no. 9, p. 2577, 2019.

[32] Q. Bai and M. Chen, "The distributionally robust newsvendor problem with dual sourcing under carbon tax and cap-andtrade regulations," Computers \& Industrial Engineering, vol. 98, pp. 260-274, 2016.

[33] Y.-T. Chang, P. T.-W. Lee, H.-J. Kim, and S.-H. Shin, “Optimization model for transportation of container cargoes considering short sea shipping and external cost,"
Transportation Research Record: Journal of the Transportation Research Board, vol. 2166, no. 1, pp. 99-108, 2010.

[34] Y. Sun and M. Lang, "Bi-objective optimization for multimodal transportation routing planning problem based on Pareto optimality," Journal of Industrial Engineering and Management, vol. 8, no. 4, pp. 1195-1217, 2015.

[35] J. Zhang, H. W. Ding, X. Q. Wang, W. J. Yin, T. Z. Zhao, and J. Dong, "Mode choice for the intermodal transportation considering carbon emissions," in Proceedings of 2011 IEEE International Conference on Service Operations, Logistics and Informatics, pp. 297-301, IEEE, Piscataway, NJ, USA, 2011 July.

[36] M. Hrušovský, E. Demir, W. Jammernegg, and T. Van Woensel, "Hybrid simulation and optimization approach for green intermodal transportation problem with travel time uncertainty," Flexible Services and Manufacturing Journal, vol. 30, no. 3, pp. 486-516, 2018.

[37] D. Zhang, R. He, S. Li, and Z. Wang, "A multimodal logistics service network design with time windows and environmental concerns," PLoS One, vol. 12, no. 9, Article ID e0185001, 2017.

[38] C. Vale and I. M. Ribeiro, "Intermodal routing model for sustainable transport through multi-objective optimization," in First International Conference on Intelligent Transport Systems, pp. 144-154, Springer, New York, NY, USA, 2018.

[39] Y. Qu, T. Bektaş, and J. Bennell, "Sustainability SI: multimode multicommodity network design model for intermodal freight transportation with transfer and emission costs," Networks and Spatial Economics, vol. 16, no. 1, pp. 303-329, 2016.

[40] H. G. Resat and M. Turkay, “A bi-objective model for design and analysis of sustainable intermodal transportation systems: a case study of Turkey," International Journal of Production Research, vol. 57, no. 19, pp. 6146-6161, 2019.

[41] Y. Chen, Z. Yuan, and B. Chen, "Process optimization with consideration of uncertainties-an overview," Chinese Journal of Chemical Engineering, vol. 26, no. 8, pp. 1700-1706, 2018.

[42] I. E. Grossmann, R. M. Apap, B. A. Calfa, P. García-Herreros, and Q. Zhang, "Recent advances in mathematical programming techniques for the optimization of process systems under uncertainty," Computers \& Chemical Engineering, vol. 91, pp. 3-14, 2016.

[43] C. Barnhart and H. D. Ratliff, "Modeling intermodal routing," Journal of Business Logistics, vol. 14, no. 1, pp. 205-223, 1993.

[44] B. S. Boardman, E. M. Malstrom, D. P. Butler, and M. H. Cole, "Computer assisted routing of intermodal shipments," Computers \& Industrial Engineering, vol. 33, no. 1-2, pp. 311-314, 1997.

[45] J. H. Bookbinder and N. S. Fox, "Intermodal routing of Canada-Mexico shipments under NAFTA," Transportation Research Part E: Logistics and Transportation Review, vol. 34, no. 4, pp. 289-303, 1998.

[46] A. Ziliaskopoulos and W. Wardell, "An intermodal optimum path algorithm for multimodal networks with dynamic arc travel times and switching delays," European Journal of Operational Research, vol. 125, no. 3, pp. 486-502, 2000.

[47] B. Ayar and H. Yaman, "An intermodal multicommodity routing problem with scheduled services," Computational Optimization and Applications, vol. 53, no. 1, pp. 131-153, 2012.

[48] L. Moccia, J.-F. Cordeau, G. Laporte, S. Ropke, and M. P. Valentini, "Modeling and solving a multimodal transportation problem with flexible-time and scheduled services," Networks, vol. 57, no. 1, pp. 53-68, 2011.

[49] H. Heggen, Y. Molenbruch, A. Caris, and K. Braekers, "Intermodal container routing: integrating long-haul routing and 
local drayage decisions," Sustainability, vol. 11, no. 6, p. 1634, 2019.

[50] D. Wolfinger, F. Tricoire, and K. F. Doerner, "A matheuristic for a multimodal long haul routing problem," EURO Journal on Transportation and Logistics, vol. 8, no. 4, pp. 397-433, 2019.

[51] H. Min, "International intermodal choices via chance-constrained goal programming," Transportation Research Part A: General, vol. 25, no. 6, pp. 351-362, 1991.

[52] A. Heinold and F. Meisel, "Emission oriented vs. Time oriented routing in the European intermodal rail/road freight transportation network," in Logistics Management, pp. 188202, Springer, New York, NY, USA, 2019.

[53] S.-T. Liu, "Fuzzy total transportation cost measures for fuzzy solid transportation problem," Applied Mathematics and Computation, vol. 174, no. 2, pp. 927-941, 2006.

[54] M. Kaur and A. Kumar, "Method for solving unbalanced fully fuzzy multi-objective solid minimal cost flow problems," Applied Intelligence, vol. 38, no. 2, pp. 239-254, 2013.

[55] P. Kundu, S. Kar, and M. Maiti, "Multi-objective multi-item solid transportation problem in fuzzy environment," Applied Mathematical Modelling, vol. 37, no. 4, pp. 2028-2038, 2013.

[56] B. Vahdani, R. Tavakkoli-Moghaddam, F. Jolai, and A. Baboli, "Reliable design of a closed loop supply chain network under uncertainty: an interval fuzzy possibilistic chance-constrained model," Engineering Optimization, vol. 45, no. 6, pp. 745-765, 2013.

[57] E. Özceylan and T. Paksoy, "Interactive fuzzy programming approaches to the strategic and tactical planning of a closedloop supply chain under uncertainty," International Journal of Production Research, vol. 52, no. 8, pp. 2363-2387, 2014.

[58] M. H. F. Zarandi, A. Hemmati, and S. Davari, "The multidepot capacitated location-routing problem with fuzzy travel times," Expert Systems with Applications, vol. 38, no. 8, pp. 10075-10084, 2011.

[59] Y. Zheng and B. Liu, "Fuzzy vehicle routing model with credibility measure and its hybrid intelligent algorithm," Applied Mathematics and Computation, vol. 176, no. 2, pp. 673-683, 2006.

[60] S. Fazayeli, A. Eydi, and I. N. Kamalabadi, "Location-routing problem in multimodal transportation network with time windows and fuzzy demands: presenting a two-part genetic algorithm," Computers \& Industrial Engineering, vol. 119, pp. 233-246, 2018.

[61] Y. Sun, X. Liang, X. Li, and C. Zhang, "A fuzzy programming method for modeling demand uncertainty in the capacitated road-rail multimodal routing problem with time windows," Symmetry, vol. 11, no. 1, p. 91, 2019.

[62] Y. Xie, W. Lu, W. Wang, and L. Quadrifoglio, “A multimodal location and routing model for hazardous materials transportation," Journal of Hazardous Materials, vol. 227-228, pp. 135-141, 2012.

[63] S. Chakraborty, K. Bhattacharjee, and S. P. Sarmah, "An effective MILP model for food grain inventory transportation in India-a heuristic approach," in Optimization and Inventory Management, pp. 361-376, Springer, New York, NY, USA, 2020.

[64] B. Sawik, "Weighted-sum approach for bi-objective optimization of fleet size with environmental aspects," in Applications of Management Science, pp. 101-116, Publishing Limited, Bingley, UK, 2018.

[65] S. J. Sharahi, A.-R. Abtahi, A. Rashidi-Komijan, and K. K. Damghani, "Type-II fuzzy multi-product, multi-level, multi-period location-allocation, Production-distribution problem in supply chains: modelling and optimisation approach," Fuzzy Information and Engineering, vol. 10, no. 2, pp. 260-283, 2018. 